Purdue University

Purdue e-Pubs

2009

Effects of Channel Dimension, Heat Flux, and Mass Flux on Flow Boiling Regimes in Microchannels

Tannaz Harirchian

S V. Garimella

Purdue University, sureshg@purdue.edu

Follow this and additional works at: http://docs.lib.purdue.edu/coolingpubs

Harirchian, Tannaz and Garimella, S V., "Effects of Channel Dimension, Heat Flux, and Mass Flux on Flow Boiling Regimes in Microchannels" (2009). CTRC Research Publications. Paper 115.

http://dx.doi.org/10.1016/j.ijmultiphaseflow.2009.01.003

This document has been made available through Purdue e-Pubs, a service of the Purdue University Libraries. Please contact epubs@purdue.edu for additional information. 


\title{
Effects of Channel Dimension, Heat Flux, and Mass Flux on Flow Boiling Regimes in Microchannels ${ }^{1}$
}

\author{
Tannaz Harirchian and Suresh V. Garimella ${ }^{2}$ \\ School of Mechanical Engineering and Birck Nanotechnology Center \\ Purdue University, 585 Purdue Mall, Purdue University \\ West Lafayette, IN 47907-2088 USA
}

\begin{abstract}
Experiments are conducted with a perfluorinated dielectric fluid, Fluorinert FC-77, to investigate the effects of channel size and mass flux (225 to $1420 \mathrm{~kg} / \mathrm{m}^{2} \mathrm{~s}$ ) on microchannel flow boiling regimes by means of high-speed photography. Seven different silicon test pieces with parallel microchannels of widths ranging from 100 to $5850 \mu \mathrm{m}$, all with a depth of $400 \mu \mathrm{m}$, are considered. Flow visualizations are performed with a high-speed digital video camera while local measurements of the heat transfer coefficient are simultaneously obtained. The visualizations and the heat transfer data show that flow regimes in the microchannels of width $400 \mu \mathrm{m}$ and larger are similar, with nucleate boiling being dominant in these channels over a wide range of heat flux. In contrast, flow regimes in the smaller microchannels are different and bubble nucleation at the walls is suppressed at a relatively low heat flux for these sizes. Two types of flow regime maps are developed and the effects of channel width on the flow regime transitions are discussed.
\end{abstract}

Keywords: two-phase flow, silicon microchannels, size effect, flow regime maps.

\footnotetext{
${ }^{1}$ Submitted for possible publication in International Journal of Multiphase Flow, October 2008, and in revised form, January 2009

${ }^{2}$ Author to whom correspondence should be addressed: (765)494-5621, sureshg@purdue.edu
} 


\section{INTRODUCTION}

Boiling in microchannel heat sinks is attractive for thermal management of high-performance electronics due to the high heat transfer rates and uniform wall temperatures that can be achieved. To develop models for the prediction of convective heat transfer coefficients based on the actual flow regimes occurring during convective boiling in microchannels, a thorough understanding of the flow patterns existing under different conditions, as well as their transitions, is necessary. In recent years, progress has been made in understanding the pressure drop and heat transfer characteristics of flow boiling in microchannels; however, a fundamental knowledge of boiling mechanisms, the effect of microchannel size on the boiling regimes, and comprehensive flow regime maps for such flows are as yet unavailable (Garimella, Singhal, and Liu 2006). A detailed investigation of the effects of microchannel size and mass flux on boiling heat transfer and pressure drop in microchannel heat sinks with a dielectric fluid was reported recently by the authors (Harirchian and Garimella 2008a). The objectives of the present study are to investigate the effects of microchannel size and mass flux on the boiling flow patterns via high-speed visualization, to propose flow regime maps for a wide range of microchannel sizes, and to explain the heat transfer data obtained in Harirchian and Garimella (2008a) in light of a knowledge of the flow patterns.

A number of studies in recent years have attempted to better understand the flow patterns during boiling in microchannels using different working fluids as reviewed in Garimella and Sobhan (2003), Sobhan and Garimella (2001), and Bertsch, Groll and Garimella (2008a). However, a systematic investigation into the effects of channel size and mass flux on the boiling flow patterns in microchannels has not been performed.

High-speed flow visualization has been employed to understand the physics of boiling in microchannels as well as the differences in the boiling regimes relative to those in conventional-sized channels. Liu, Lee, and Garimella (2005) studied the onset of nucleate boiling in water flow through microchannels of $275 \mu \mathrm{m} \times 636 \mu \mathrm{m}$ cross section via high-speed flow visualization and developed an analytical model to predict the incipience heat flux and bubble size at the onset of boiling. Peng and 
Wang (1993) experimentally investigated flow boiling of water in microchannels of cross section $600 \mu \mathrm{m}$ $\times 700 \mu \mathrm{m}$. They showed that unlike larger tubes, partial nucleate boiling was not observed in the subcooled region, and fully developed boiling was induced much earlier than at the macroscale. Kew and Cornwell (1997) experimentally studied two-phase flow regimes and heat transfer with refrigerant R141b in circular tubes of diameters in the range of 1.39 to $3.69 \mathrm{~mm}$. They observed flow regimes that differed slightly from those observed in large channels and found that three flow regimes of isolated bubble flow, confined bubble flow, and annular-slug flow were sufficient to describe the observed patterns. They also showed that for narrow channels having a confinement number of 0.5 and larger, conventional correlations were not suitable for the prediction of flow boiling heat transfer and that nucleate boiling correlations such as that of Cooper (1984a) predict the data better than the established correlations for flow boiling. Huo et al. (2004) investigated boiling heat transfer with R134a in small-diameter tubes at mass fluxes ranging from 100 to $500 \mathrm{~kg} / \mathrm{m}^{2} \mathrm{~s}$. Their visualizations revealed six flow patterns: dispersed bubble, bubbly, slug, churn, annular, and mist flow. It was also shown that nucleate boiling was dominant for vapor qualities less than 40-50\% (20-30\%) for tubes of diameter 4.26 (2.01) mm. Kandlikar (2004) observed features such as flow reversal and nucleate boiling-dominant heat transfer in microchannel flow boiling as well as flow patterns of slug flow, annular flow, churn flow, and dryout. Revellin et al. (2006) studied two-phase flow patterns of R134a in a $500 \mu \mathrm{m}$ glass channel and delineated four flow patterns of bubbly, slug, semi-annular, and annular flows. The frequency of bubble generation, coalescence rate and mean bubble velocity were also determined. Chen and Garimella (2006a) conducted experiments to study the physics of boiling in parallel silicon microchannels with a cross section of $389 \mu \mathrm{m} \times 389 \mu \mathrm{m}$ using FC-77 as the working fluid. Three flow rates ranging from 260 to $445 \mathrm{~kg} / \mathrm{m}^{2} \mathrm{~s}$ were tested. They observed bubbly and slug flow patterns at lower heat fluxes and wispy-annular and churn flow regimes at higher heat fluxes with flow reversal near the microchannel inlet.

Other studies have utilized flow visualization to record the flow patterns under different flow conditions and with specific geometries. Jiang, Wong, and Zohar (2001) carried out experiments with water in triangular silicon microchannels of hydraulic diameter 26 and $53 \mu \mathrm{m}$ and observed local nucleate boiling at low input power and unstable slug flow at intermediate power levels. However, annular flow 
developed at a relatively low heat flux, such that evaporation at the liquid film/vapor core interface was the dominant heat transfer mode over a wide range of input powers. Wang, Cheng, and Bergles (2008) performed experiments to investigate the effect of inlet/outlet configurations on flow boiling instabilities with water in parallel microchannels of hydraulic diameter $186 \mu \mathrm{m}$. They observed bubbly/slug flow, bubbly/annular alternating flow, and annular/mist alternating flow when the flow could freely enter and exit the microchannels. In the case of flow being restricted at the channel inlet but not at the outlet, steady flow boiling patterns of isolated bubbles, elongated bubbles, and annular flow were seen. Zhang, Pinjala, and Wong (2005) performed an experimental study of flow boiling with FC-72 for three different orientations of a microchannel heat sink: vertical up-flow, vertical down-flow, and horizontal flow. The heat sink consisted of parallel microchannels $200 \mu \mathrm{m}$ wide and $2 \mathrm{~mm}$ deep. They observed boiling to occur in isolated bubble and slug flow regimes and found that the vertical up-flow orientation had the best thermal performance, highest flow stability, and lowest pressure drop. Differences between the flow regimes with air-water and steam-water experiments were observed in the visualizations of Hetsroni et al. (2003) in parallel triangular channels etched in a silicon substrate with a base dimension of 200 to 310 $\mu \mathrm{m}$.

Only a few of these studies have utilized the observed flow patterns to develop flow regime maps for boiling in microchannels. Hetsroni et al. (2003) proposed a flow regime map for transition from a low heat flux region, characterized by the presence of liquid phase in all microchannels, to a high heat flux region, characterized by a periodic dryout phenomenon, for boiling of water in parallel triangular microchannels. Huo et al. (2004) also proposed a flow regime map for R134a in a small tube. Two regime maps developed for larger tubes by Taitel (1990) and Mishima and Ishii (1984) were compared to their map for the small tube and were shown to be inapplicable for predicting flow regime transitions. Revellin et al. (2006) constructed flow regime maps for R134a in a $500 \mu$ m-diameter tube in terms of mass flux versus vapor quality and superficial liquid velocity versus superficial vapor velocity. They compared their flow pattern transitions to those of macroscale refrigerant flow and microscale air-water flow, neither of which matched their results well. 
Adiabatic two-phase flow patterns were investigated through high-speed visualizations and flow regime maps developed by Chung and Kawaji (2004), Hassan, Vaillancourt, and Pehlivan (2005), and Field and Hrnjak (2007). Field and Hrnjak (2007) showed that the flow maps developed for large channels were not suitable for prediction of the flow regimes in microchannels; also, flow maps were dependent on the specific fluid for which they were developed. Despite the inability of macroscale boiling maps or adiabatic two-phase flow regime maps to predict the flow patterns for boiling in microchannels, a review of the literature shows a dearth of investigations into flow regime maps specifically targeted at microchannels undergoing flow boiling.

Although microchannel flow boiling has been an active field of study, few investigations have systematically explored the effects of microchannel dimensions and mass flux on the flow patterns and heat transfer characteristics, as summarized by Harirchian and Garimella (2007). Lin, Kew, and Cornwell (2001) and Saitoh, Daiguji, and Hihara (2005) studied the effects of mass flux and channel diameter on boiling heat transfer coefficients for refrigerants in small channels. Bertsch, Groll, and Garimella (2008b) and Chen and Garimella (2006a) studied the effect of mass flux on boiling in microchannels using refrigerant and FC-77, respectively. Lee et al. (2003) explored the effect of channel shape and Zhang et al. (2005) investigated the effects of hydraulic diameter and surface roughness on two-phase flow patterns in water. Lee and Mudawar (2008) explored the effects of hydraulic diameter, mass velocity and subcooling on boiling flow patterns with HFE-7100.

Use of dielectric liquids in microchannel heat sinks has drawn recent attention since the working fluid in the microchannel heat sinks can then be in direct contact with the electronics. Perfluorocarbons are particularly suitable for direct contact cooling due to their high electrical resistivity. Although there have been a number of studies on pool boiling of perfluorocarbon liquids and the effect of surface enhancement (Honda and Wei 2004, McHale and Garimella 2008), investigations of flow boiling patterns in microchannels using perfluorocarbon liquids have been limited (Zhang, Pinjala, and Wong 2005, Lee and Mudawar 2008, Chen and Garimella 2006a).

The present work seeks to address the limited understanding in the literature of the effects of channel size and mass flux on boiling flow patterns in microchannels. The results are also aimed at explaining the 
effects of channel size, mass flux and heat flux on the boiling heat transfer coefficients previously obtained in the same facility (Harirchian and Garimella 2008a). As discussed above, existing flow regime maps for boiling in microchannels are limited to a narrow range of channel sizes and have been developed with water and refrigerants. Flow regime maps are developed in this study for boiling of FC-77 in microchannel heat sinks with a wide range of channel dimensions, and the effect of channel width on the transitions between flow regimes is investigated.

\section{EXPERIMENTAL SETUP AND TEST PROCEDURES}

In this section the salient features of the experimental test loop, the test section, and the test procedures are briefly explained. A more detailed description including the test-piece calibration processes is available in Harirchian and Garimella (2008a).

\subsection{Flow loop}

The experimental setup is shown in Figure 1. The test loop includes a magnetically coupled gear pump that drives the dielectric liquid, FC-77, through the closed loop, a preheater installed upstream of the test section, the microchannel heat sink, a liquid-to-air heat exchanger located downstream of the test section, and an expandable reservoir. The preheater heats the coolant to the desired subcooling temperature at the entrance of the microchannels and the heat exchanger cools the fluid before it enters the reservoir. The expandable reservoir is used to fully degas the liquid before initiating each test. Details of the expandable reservoir design and the degassing procedure are available in Chen and Garimella (2006b). A flow meter monitors the flow rate through the loop, while five T-type thermocouples measure the fluid temperature before and after the preheater, before and after the test section, and after the heat exchanger. The pressure in the outlet manifold of the test section is maintained at 1 atmosphere. The pressure at the inlet manifold and the pressure drop across the microchannel array are measured using a pressure transducer and a differential pressure transducer, respectively. A highspeed digital video camera (Photron Fastcam-Ultima APX) is employed for flow visualizations. The high-speed camera provides full-pixel resolution of $1024 \times 1024$ at up to 2,000 frames per second (fps) and is capable of recording at frame rates as high as $120,000 \mathrm{fps}$ with reduced resolution. Different 
microscope lenses, depending on the microchannel size, are used for magnification. An illumination source (Henke-Sass Wolf) is used to illuminate the microchannels for visualization. Using the same experimental setup, Chen and Garimella (2006a) showed that this illumination source does not result in additional heat input to the fluid.

\subsection{Test section}

Figure 2 shows the assembled test section. It consists of a $12.7 \mathrm{~mm} \times 12.7 \mathrm{~mm}$ silicon chip with parallel microchannels of rectangular cross section cut into the top surface using a dicing saw. Experiments are conducted for seven test pieces with a constant channel depth of $400 \mu \mathrm{m}$ and different channel widths ranging from $100 \mu \mathrm{m}$ to $5850 \mu \mathrm{m}$, with the channel length held constant at $12.7 \mathrm{~mm}$. The actual and nominal dimensions of the test pieces including channel width, $w$, fin width, $w_{f}$, channel depth, $H$, and number of microchannels, $N$, are summarized in Table 1 .

A $5 \times 5$ array of resistors and a like array of temperature sensing diodes are fabricated on the underside (Harirchian and Garimella 2007), providing uniform heat flux to the base of the microchannels and local measurements of the base temperature at 25 locations.

The silicon heat sink is mounted on a printed circuit board (PCB) which is installed on a quickconnect board with an insulating G10 piece in between. A polycarbonate top cover above the test piece provides an enclosed passage for the liquid and is sealed with an o-ring. After entering the inlet manifold, the liquid travels through a rectangular manifold of cross section $12.7 \mathrm{~mm} \times 1.05 \mathrm{~mm}$ which is $13 \mathrm{~mm}$ in length before entering the microchannels. The exit manifold is recessed such that the vapor generated in the heat sink escapes as it exits the microchannels and does not block the flow. A $12.7 \mathrm{~mm} \times 12.7 \mathrm{~mm}$ Pyrex sheet of thickness $0.4 \mathrm{~mm}$ with a high melting point is sandwiched between the silicon chip and the top cover to avoid melting of the polycarbonate at high chip temperatures and to form the top wall of the microchannels.

The bottom wall of the $100 \mu \mathrm{m}$-wide microchannels has an average roughness of $0.1 \mu \mathrm{m}$. Wider microchannels were made with a number of cuts; this process imparts a waviness to the bottom surfaces resulting in an average roughness of 0.8 to $1.4 \mu \mathrm{m}$ for the different test pieces; the average roughness in the region of a single cut in these wider channels is $0.2 \mu \mathrm{m}$. 


\subsection{Experimental procedures}

Experiments are performed for seven test pieces to study the effect of microchannel width on the boiling flow patterns and the heat transfer coefficients. Four mass fluxes ranging from 225 to 1420 $\mathrm{kg} / \mathrm{m}^{2} \mathrm{~s}$ are investigated for each test piece. The average values of mass flux are listed in Table 1.

All of the embedded resistors and the integrated diode temperature sensors are first calibrated in a precision oven. The liquid in the test loop is fully degassed before initiating each test. It is then driven into the loop at a constant flow rate and preheated to approximately $92^{\circ} \mathrm{C}$, providing $5 \mathrm{~K}$ of subcooling at the inlet of the channels. For each test, the flow rate and the inlet fluid temperature are kept constant throughout the test and the heat flux to the chip is increased from zero to the point at which the maximum wall temperature reaches $150^{\circ} \mathrm{C}$, which is the maximum safe operating temperature for the integrated temperature sensors. It is emphasized that the heat flux is maintained uniform over the base area of the chip. At each heat flux and after the system reaches a steady state, high-speed visualizations are performed simultaneously with the heat transfer and pressure drop measurements. Movies of the flow patterns are captured with various frame rates ranging from 2,000 frames per second (fps) to $24,000 \mathrm{fps}$, with the higher frame rates used for the smaller microchannels at the larger mass fluxes. Also, as the heat flux is increased, the vapor velocity increases and higher frame rates are required to capture the details of the flow. The images obtained from the camera are then post-processed using a MATLAB code developed in-house to enhance the quality of the images, especially for those captured at higher frame rates. Flow visualizations have been performed for six of the seven test pieces at different flow rates.

It is noted that all the values of heat transfer coefficient and wall temperature reported in this study are based on the local temperature measurement at a location near the exit and along the centerline of the microchannel array. The flow visualizations are performed at this location as well.

\subsection{Data reduction}

The local heat transfer coefficient is calculated from

$$
h=\frac{q_{w}^{\prime \prime}}{\eta_{o}\left(T_{w}-T_{\text {sat }}\right)}
$$


where $T_{\text {sat }}$ is the liquid saturation temperature and $T_{w}$ is the local microchannel wall temperature as obtained from the temperature measured by the integrated diode sensor, and is corrected for conduction through the microchannel base thickness. In equation (1), $\eta_{o}$ is the overall surface efficiency of the microchannels defined as $\eta_{o}=1-\frac{N A_{f}}{A_{w}}\left(1-\eta_{f}\right)$, where $A_{f}=2 L H$ is the wetted area of a fin and $\eta_{f}=\frac{\tanh m d}{m d}$ is the efficiency of a fin with an adiabatic tip, with $m^{2}=2 h / k_{s i} w_{f}$. Here, $w_{f}$ is the fin width and $k_{s i}$ is the silicon thermal conductivity. The overall surface efficiency ranges from $96.5 \%$ to $99.9 \%$ for the heat sinks considered.

The wall heat flux, $q_{w}^{\prime \prime}$, is defined as

$$
q_{w}^{\prime \prime}=\dot{q}_{n e t} /\left(A_{w} / 25\right)
$$

The area $A_{w}$ is the total heated area in the microchannels:

$$
A_{w}=N(w+2 H) L
$$

Here, $N$ is the number of microchannels in a heat sink, and $w, H$, and $L$ are the microchannel width, depth, and length, respectively.

The net heat transfer rate to the fluid, $\dot{q}_{n e t}$, is obtained from the energy balance for each heating element:

$$
\dot{q}_{\text {net }}=\dot{q}-\dot{q}_{\text {loss }}
$$

in which $\dot{q}$ is the total heat dissipated from each heat source and $\dot{q}_{\text {loss }}$ is the heat loss which is experimentally determined before the test assembly is charged with coolant. Details of the heat loss measurement procedure and data reduction can be found in Harirchian and Garimella (2008a). The heat loss values range from $7 \%$ to $50 \%$ of the net heat transfer rate for different test pieces and different mass fluxes and are larger for wider microchannels at lower mass fluxes.

The uncertainties in the measurement of the channel dimensions, the T-type thermocouples and the mass flux are $\pm 15 \mu \mathrm{m}, \pm 0.3 \mathrm{~K}$, and 2-5\%, respectively. The uncertainty introduced through the calibration 
procedure into the diode temperature sensor measurement is calculated to be $\pm 0.02 \mathrm{~K}$; the oven temperature measurements during the calibration process have an uncertainty of $\pm 0.3 \mathrm{~K}$, and this is the value of uncertainty assigned to the wall temperature measurement. Uncertainties in the flow meter and pressure transducer readings are $1 \%$ and $0.25 \%$ of full scale, respectively. Using a standard uncertainty analysis (Taylor 1997), the uncertainties associated with the wall heat flux and the heat transfer coefficient are estimated to be 2 to $4 \%$ and 2.2 to $4.8 \%$, respectively, for the cases considered.

\section{RESULTS AND DISCUSSION}

In this section, the flow visualizations are analyzed and the effects of channel dimensions, mass flux, and heat flux on the boiling flow patterns discussed. The flow patterns are also used to support the conclusions from previous studies (Harirchian and Garimella 2008a, b) using the same facility on the effects of channel size and mass flux on flow boiling heat transfer in microchannels. Flow regime maps are then developed and the effect of channel dimensions on flow regime transitions is explored.

\subsection{Flow patterns}

In the microchannels studied, flow patterns observed via high-speed visualizations are categorized into five major flow regimes - bubbly, slug, churn, wispy-annular, and annular flows; a post-dryout regime of inverted-annular flow is also identified. Although these flow patterns have a slightly different appearance in different channel sizes and for different mass fluxes and flow rates, each is characterized by certain common features. These flow patterns are first explained with respect to the $400 \mu \mathrm{m} \times 400 \mu \mathrm{m}$ microchannels.

Representative visualized images in these six flow regimes are illustrated in Figure 3. In all the flow visualization images in this paper, the flow direction is from left to right. For better delineation of the liquid and vapor phases in the flow patterns, a sketch of the flow pattern is added on the right side of each image. Figure 3(a) shows bubbly flow in which isolated round and elongated bubbles that are smaller than the cross section of the microchannels move in the flow direction. Bubbles generally nucleate at the microchannel walls and detach from the walls after growing. The shape and size of the bubbles vary with flow rate and heat flux. As the heat flux increases, the bubble generation rate at the walls increases and 
bubbles become larger as a result of bubble coalescence. At higher heat fluxes or in smaller microchannels, bubbles occupy the entire cross section of the channels, resulting in slug flow as shown in Figure 3(b); small bubbles exist in the liquid slugs between the elongated bubbles. The churn flow regime is demonstrated in Figure 3(c). This flow regime consists of vapor chunks transported downstream and large bubbles nucleating at a high rate at the channel walls; however, at high heat fluxes, the nucleation at the walls may be suppressed. In wispy-annular flow as in Figure 3(d), a vapor core is separated from the channel walls with a relatively thick and unstable liquid film. Large, irregular-shaped droplets are entrained into the vapor core. Very few nucleation sites remain in the liquid film and result in small vapor bubbles in the liquid layer. In annular flow, as illustrated in Figure 3(e), the liquid layer is thinner than in wispy-annular flow, and the interface between the vapor core and the liquid film can become wavy. The liquid film thickness decreases as the heat flux increases. Small, round droplets are entrained into the vapor core, while no vapor bubbles are seen in the liquid annulus. At vey high heat fluxes, when critical heat flux is reached, the walls can completely dry out under certain conditions and a vapor blanket forms at the walls around a liquid core flowing through the center of the channels. This flow regime is called inverted-annular flow (Figure 3(f)) and was seen in some of the tests. This flow regime is to be avoided since it is accompanied with a sudden rise in the wall temperature and a significant drop in the heat transfer coefficient.

Under some conditions, these flow patterns may alternate in a single channel, resulting in an intermittent flow. In channels with large aspect rations, two different flow patterns may also be present alongside each other across the width of the channels. In subsequent sections, the conditions for the occurrence of these flow patterns are discussed for different channel sizes and different mass fluxes.

\subsubsection{Effect of channel width on flow patterns}

Flow patterns visualized in the heat sinks with microchannels of different widths are presented and discussed in this section for the mass flux of $630 \mathrm{~kg} / \mathrm{m}^{2} \mathrm{~s}$.

In the $100 \mu \mathrm{m}$-wide microchannels, the flow patterns are different from those observed in the larger microchannels, likely due to the small diameter and the resulting confinement effects. These flow patterns are depicted in Figure 4 for four heat fluxes at a mass flux of $630 \mathrm{~kg} / \mathrm{m}^{2} \mathrm{~s}$. At this microchannel 
width, bubbly flow is not established at the visualization location, and instead, slug flow commences early after the incipience of boiling. Figure 4(a) shows the boiling patterns right after the commencement of boiling. As can be seen in the photograph, the vapor slugs are separated by a few small bubbles in the bulk liquid. However, these small bubbles disappear at a heat flux as low as $33.7 \mathrm{~kW} / \mathrm{m}^{2}$.

At a heat flux of $44.8 \mathrm{~kW} / \mathrm{m}^{2}$, the tail of the slugs breaks up and is no longer very distinguishable. The liquid layer between the vapor core and the walls also breaks up at the locations in which bubbles nucleate on the walls. As shown in Figure 4(b), the liquid layer breaks into rivulets forming a discontinuous liquid layer at the walls.

As the heat flux is increased to $62 \mathrm{~kW} / \mathrm{m}^{2}$, flow enters an annular regime. The liquid layer surrounding the vapor core in the annular flow alternates between a smooth annulus and a discontinuous layer as shown in Figure 4(c) for the heat flux of $71.5 \mathrm{~kW} / \mathrm{m}^{2}$. In the discontinuous annular flow, bubble nucleation at the walls is still seen in the discontinuous liquid annulus up to a heat flux of $82.1 \mathrm{~kW} / \mathrm{m}^{2}$, beyond which bubble nucleation at the walls is suppressed. Unlike the larger microchannels, no droplets are observed in the vapor core of the annular flow.

At heat fluxes higher than $92.3 \mathrm{~kW} / \mathrm{m}^{2}$, an intermittent churn and annular flow appears. This intermittent flow regime is shown in Figure 4(d) for a heat flux of $102.7 \mathrm{~kW} / \mathrm{m}^{2}$. Although the top wall of the microchannel partially dries out at heat fluxes exceeding $62 \mathrm{~kW} / \mathrm{m}^{2}$, the side walls do not seem to dry out even at very high heat fluxes.

In the $400 \mu \mathrm{m} \times 400 \mu \mathrm{m}$ microchannel heat sink at a mass flux of $630 \mathrm{~kg} / \mathrm{m}^{2} \mathrm{~s}$, three general flow patterns are observed as the heat flux is increased - bubbly flow, alternating churn and wispy-annular flow, and alternating churn and annular flow - as illustrated in Figure 5. Bubbly flow starts after the onset of boiling at q" $=64.8 \mathrm{~kW} / \mathrm{m}^{2}$, with isolated round and elongated bubbles. As the heat flux increases the bubbles coalesce and generate larger and longer bubbles. At this flow rate, bubbles do not span the width of the channels and slug flow does not occur. As the heat flux is increased to 132.6 $\mathrm{kW} / \mathrm{m}^{2}$, the flow pattern becomes intermittent, alternating between churn flow and wispy-annular flow. Very few nucleation sites remain in the liquid film in the wispy-annular regime. For heat fluxes of 156.5 $\mathrm{kW} / \mathrm{m}^{2}$ and higher, annular flow replaces the wispy-annular regime in the intermittent flow. Small, round 
droplets are entrained into the vapor core. As the heat flux is further increased to $220.2 \mathrm{~kW} / \mathrm{m}^{2}$, careful observation of the churn flow shows that bubbles no longer nucleate at the walls and all the vapor chunks arrive from further upstream with a very thin liquid layer separating them from the walls. At this heat flux, the nucleate boiling-dominant regime seems to end and boiling enters a convective-dominant region; the heat transfer results discussed later in section 3.2.2 (and in Figure 12) are consistent in this transition in the boiling regime identified through visualizations.

Figure 6 shows the flow patterns observed in the $5850 \mu \mathrm{m}$-wide microchannels at a mass flux of 630 $\mathrm{kg} / \mathrm{m}^{2} \mathrm{~s}$. It is emphasized that channel depth remains at $400 \mu \mathrm{m}$ for all the microchannel widths tested; some of the results observed are no doubt a function of channel depth as well and this parameter is being investigated in detail in ongoing work by the authors. Bubbles start nucleating at the walls at a heat flux of $45 \mathrm{~kW} / \mathrm{m}^{2}$ and when the heat flux reaches $59.7 \mathrm{~kW} / \mathrm{m}^{2}$, bubbly flow similar to that in the $400 \mu \mathrm{m}$-wide microchannels begins. Figure 6(a) shows the bubbly flow at a heat flux of $77.1 \mathrm{~kW} / \mathrm{m}^{2}$. As the heat flux increases, some bubbles grow bigger and fill the height of the channel while expanding laterally, as shown in Figure 6(b). Increasing the heat flux further to $194 \mathrm{~kW} / \mathrm{m}^{2}$ leads to the commencement of churn/wispyannular flow. Unlike the $400 \mu \mathrm{m}$-wide microchannels, these two flow regimes do not necessarily follow each other along the length of the channel; instead, they are distributed side by side across the width of the channel due to the large aspect ratio. As can be seen in Figure 6(c) for a heat flux of $221.7 \mathrm{~kW} / \mathrm{m}^{2}$, large liquid droplets exist in the vapor core in the wispy-annular flow. At the highest heat flux of 270 $\mathrm{kW} / \mathrm{m}^{2}$, annular flow replaces the wispy-annular regime where small liquid droplets are entrained in the vapor core as shown in Figure 6(d). A careful study of the flow visualizations indicates that bubble nucleation ceases at the downstream end of the channels at a heat flux of $255 \mathrm{~kW} / \mathrm{m}^{2}$.

Figure 7 summarizes the flow patterns observed across the wide range of microchannel widths considered in this work at four mass fluxes. It is clear from the summary in this figure that the boiling flow patterns in the microchannels of width 1000 and $2200 \mu \mathrm{m}$ are very similar to the ones observed in the $5850 \mu \mathrm{m}$-wide microchannels and the transitions between different flow patterns occur at similar values of heat flux for these three microchannel widths. The difference, however, is that intermittent bubbly and slug flow occurs in the 1000 and $2200 \mu \mathrm{m}$-wide microchannels at low mass fluxes, while slug 
flow does not occur in the $5850 \mu \mathrm{m}$ microchannels at any mass flux. At the other end, in the $250 \mu \mathrm{m}$ wide microchannels, as in the $100 \mu \mathrm{m}$-wide microchannels, the regime of intermittent churn and wispyannular flow is not observed. Unlike the $100 \mu \mathrm{m}$-wide microchannels in which bubbly flow was not observed, intermittent bubbly and slug flow is seen at intermediate mass fluxes for the $250 \mu \mathrm{m}$ width and bubbly flow is detected at higher flow rates.

In general, it is noted from this figure that the incipience heat flux (at which boiling starts) and the critical heat flux (at which the wall dries out and results in a sharp increase in wall temperature) increase with increasing mass flux and increasing channel width. It may also be concluded that bubbly flow replaces slug flow, and intermittent churn/wispy-annular flow replaces intermittent churn/annular flow, as the channel width or the mass flux increase.

\subsubsection{Effect of mass flux on flow patterns}

The effect of mass flux on the flow patterns is discussed with respect to the microchannels of width $400 \mu \mathrm{m}$ at four mass fluxes of 225, 630, 1050, and $1420 \mathrm{~kg} / \mathrm{m}^{2} \mathrm{~s}$. As depicted in Figure 5 and discussed in the previous section, the main flow regimes for the mass flux of $630 \mathrm{~kg} / \mathrm{m}^{2} \mathrm{~s}$ are bubbly flow, intermittent churn and wispy-annular flow, and intermittent churn and annular flow. As the mass flux decreases or increases, these flow patterns change, as does the heat flux at which transitions between the observed flow regimes occur.

Figure 8 shows the flow patterns immediately after the incipience of boiling at the four mass fluxes tested. It is seen that as the mass flux increases, boiling commences at a higher heat flux. Also, the bubbly flow regime appears different as the mass flux increases. For the lower mass flux of $225 \mathrm{~kg} / \mathrm{m}^{2} \mathrm{~s}$, some bubbles grow larger and span the cross-section of the channel, leading to a bubbly-slug flow regime as soon as boiling starts, as depicted in Figure 8(a). As the heat flux increases at this flow rate, these vapor slugs coalesce and generate very long vapor slugs with smaller bubbles following them in the flow (not shown in the figure). As the mass flux increases, bubbles become smaller but are more elongated at the incipience of boiling. For mass fluxes of $630 \mathrm{~kg} / \mathrm{m}^{2} \mathrm{~s}$ and higher, the bubbles are relatively small at the incipience of boiling (Figure 8(b-d)) and as the heat flux increases, the size and number of bubbles 
and the rate of bubble coalescence all increase, resulting in larger and longer bubbles; however, slug flow does not occur at any heat flux.

As discussed earlier, for the mass flux of $630 \mathrm{~kg} / \mathrm{m}^{2} \mathrm{~s}$, an intermittent churn and wispy-annular flow regime arises following the bubbly flow regime, and annular flow replaces the wispy-annular regime at higher heat fluxes. A close observation of the annular flow pattern for mass fluxes of 225 and $630 \mathrm{~kg} / \mathrm{m}^{2} \mathrm{~s}$ shows that the liquid film thickness decreases and the vapor-liquid interface becomes wavy as the mass flux or heat flux increase, due to an increase in the vapor velocity.

For the mass flux of $225 \mathrm{~kg} / \mathrm{m}^{2} \mathrm{~s}$, the wispy-annular regime is not seen and the flow enters an intermittent churn and annular flow regime after the bubbly/slug regime. At the higher mass flux of 1050 $\mathrm{kg} / \mathrm{m}^{2} \mathrm{~s}$, intermittent churn and wispy-annular flow follows the bubbly flow regime; however, annular flow is not observed at this mass flux. For the largest mass flux considered of $1420 \mathrm{~kg} / \mathrm{m}^{2} \mathrm{~s}$, bubbly flow changes to churn flow as the heat flux increases and an intermittent flow and annular regime are not observed. A careful study of the flow pattern transitions in Figure 7 for the $400 \mu \mathrm{m} \times 400 \mu \mathrm{m}$ microchannels indicates that the transition from bubbly to intermittent flow, or to churn flow in the case of $1420 \mathrm{~kg} / \mathrm{m}^{2} \mathrm{~s}$, occurs at higher heat fluxes as the mass flux increases.

Since the transition between specific flow patterns occurs at higher heat fluxes as the mass flux increases, different flow regimes are seen at a given heat flux for different mass fluxes. Figure 9 presents the flow patterns at a heat flux of $145 \pm 2 \mathrm{~kW} / \mathrm{m}^{2}$ for four different mass fluxes in the microchannels of width $400 \mu \mathrm{m}$. It is seen that intermittent flow has started for the mass fluxes of 225 and $630 \mathrm{~kg} / \mathrm{m}^{2} \mathrm{~s}$, while for the mass fluxes of 1050 and $1420 \mathrm{~kg} / \mathrm{m}^{2} \mathrm{~s}$, the flow is still in the bubbly regime. Also, the visualizations reveal that the flow has entered a convective boiling-dominant regime for the mass flux of $225 \mathrm{~kg} / \mathrm{m}^{2} \mathrm{~s}$ at this heat flux, while for the other three mass fluxes, flow is still in the nucleate boiling regime.

\subsection{Heat transfer coefficient}

The boiling heat transfer coefficients and boiling curves for the $400 \mu \mathrm{m} \times 400 \mu \mathrm{m}$ microchannels are first considered at a mass flux of $630 \mathrm{~kg} / \mathrm{m}^{2} \mathrm{~s}$. The observed effects of channel size and mass flux on the heat transfer coefficient are then explained with the aid of the flow patterns presented in this work. 
In Figure 10, the heat transfer coefficient and wall temperature corresponding to the visualizations in Figure 5 are plotted as a function of the wall heat flux. It is seen that the onset of boiling is accompanied with a sudden increase in the heat transfer coefficient and a drop in the wall temperature. Once boiling commences, the increase in wall temperature with heat flux in the nucleate boiling regime is moderate relative to the single phase region in which wall temperature increases significantly with heat flux. At a heat flux of $234.1 \mathrm{~kW} / \mathrm{m}^{2}$, partial dry-out is observed on the side walls in the annular flow regime, and this is responsible for the drop in the heat transfer coefficient and the increase in wall temperature observed in the figure.

\subsubsection{Effect of channel width on heat transfer coefficient}

As discussed in detail in an earlier study (Harirchian and Garimella 2008a) and shown for a representative case in Figure 11, the heat transfer coefficient is nearly invariant for a given heat flux as the microchannel width increases beyond $400 \mu \mathrm{m}$. With the aid of the flow visualizations in the present study, the independence of heat transfer coefficient on channel width for microchannels wider than 400 $\mu \mathrm{m}$ can be understood.

The transition from bubbly or slug flow to the intermittent flow at a mass flux of $630 \mathrm{~kg} / \mathrm{m}^{2} \mathrm{~s}$ occurs at a very low heat flux for the 100 and $250 \mu \mathrm{m}$-wide microchannels compared to the $400 \mu \mathrm{m}$-wide and larger microchannels (Figure 7). Also, transition from the nucleate boiling regime to the convective boiling regime occurs at a very low heat flux for these small microchannels. The heat fluxes at which nucleation is no longer observed at the channel walls are denoted on Figure 11 with arrows. It is seen that nucleate boiling is dominant up to very high heat fluxes for microchannel widths of $400 \mu \mathrm{m}$ and more, resulting in very similar values of heat transfer coefficient irrespective of channel width; however, for the 100 and $250 \mu \mathrm{m}$ wide microchannels, nucleate boiling is suppressed at a relatively low heat flux, and leads to a distinct behavior of the heat transfer coefficient curves.

Harirchian and Garimella (2008a) compared heat transfer coefficients obtained from their experiments to several correlations from the literature. They found that the nucleate pool boiling correlation of Cooper (1984b) predicted the experimental results very well, except for the low flow rates in the 100 and $250 \mu$ m-wide microchannels. This observation can be explained based on the 
visualizations from the current study which show that the transition to intermittent annular flow and the suppression of nucleate boiling occur at very low heat fluxes for the 100 and $250 \mu \mathrm{m}$ widemicrochannels, while for the channels of $400 \mu \mathrm{m}$ width and higher, nucleate boiling is dominant over a wide range of heat fluxes. Kew and Cornwell (1997) also showed that the nucleate pool boiling correlation of Cooper (1984a) predicted their experimental results better than the existing correlations for flow boiling.

\subsubsection{Effect of mass flux on heat transfer coefficient}

In Figure 12 heat transfer coefficients are plotted versus the wall heat flux for both single-phase and two-phase regions in the $400 \mu \mathrm{m} \times 400 \mu \mathrm{m}$ microchannels. The transition from single-phase to two-phase flow can be easily distinguished from the sudden increase in the heat transfer coefficient. The curves in Figure 12 reveal that the boiling incipience heat flux and the critical heat flux increase as the mass flux increases, as also discussed earlier.

As seen in Figure 12, the plots of heat transfer coefficient for different mass fluxes collapse on to a single curve after the onset of boiling. At high heat fluxes, however, the curves again deviate from each other. In Harirchian and Garimella (2008a), the reason for this behavior was discussed to be the dominance of the nucleate boiling regime after the onset of boiling, and the dominance of convective boiling at the location where each curve begins to deviate from the others. Flow visualizations in the current study confirm this conjecture; a careful study of the flow patterns reveals that in general the bubble nucleation at the walls is not suppressed as the bubbly flow ends and the churn flow or the intermittent flow begin. Although not many nucleation sites are seen in the liquid film of the annular flow, bubbles still nucleate at the walls in the churn flow. As the heat flux is increased further, nucleation at the wall stops and a very thin liquid layer appears to surround the churn flow. The heat flux at which bubble nucleation is visually observed to be suppressed is shown in Figure 12 with arrows. These heat fluxes are consistent with the points at which the heat transfer coefficient curves deviate from each other and convective boiling dominates.

At very high heat fluxes, for the mass fluxes of 225 and $630 \mathrm{~kg} / \mathrm{m}^{2} \mathrm{~s}$, the side walls partially dry out. As annotated in Figure 12, this results in a sudden drop in the heat transfer coefficient. 


\subsection{Flow regime maps}

Given the complex effects observed in the flow patterns of changes in channel width, heat flux and mass flux, flow regime maps are developed here to assist in the practical design of microchannel heat sinks that rely on two-phase heat transport. Two different types of flow regime maps are developed based on the observed flow patterns. In the first, mass flux is plotted versus vapor quality, and in the second, liquid and vapor superficial velocities are chosen as the coordinates, as is common in the literature. While in developing the mass flux-quality flow regime map, the required quantities are measured directly from the experiments, superficial velocities for the second type of flow map are obtained by assuming that each phase occupies the entire channel cross-section and are calculated from $j_{f}=(1-x) G / \rho_{f}$ and $j_{g}=x G / \rho_{g}$ for the liquid and vapor phases, respectively. In these equations, $\mathrm{G}$ and $\mathrm{x}$ are mass flux and vapor quality, and $\rho_{f}$ and $\rho_{g}$ are the liquid and vapor densities, respectively.

Figure 13 shows the mass flux versus vapor quality flow regime maps for six microchannel widths. The experimental data points are represented by different symbols for different flow patterns and the transitions between the flow regimes are presented by lines.

In general it is seen that transition to intermittent churn and wispy-annular or annular flow occurs at a lower vapor quality as the mass flux increases. Figure 13 indicates that the flow patterns, and hence the flow maps, are different for boiling in microchannels of different sizes. For instance, churn/wispyannular flow does not occur in the smaller microchannels. It also appears that slug flow tends to exist in smaller microchannels with lower mass fluxes and is replaced by bubbly flow as the microchannel size or mass flux is increased. For the 250 and $1000 \mu \mathrm{m}$-wide microchannels, the input heat flux exceeded the critical heat flux and inverted annular flow, which is a post-dryout regime, was observed; transition from the intermittent churn and annular flow to the post-dryout regime is shown in the corresponding flow maps. As the mass flux or channel width increases, the transition to post-dryout occurs at a lower vapor quality. Figure 14 shows the flow maps for different heat sinks using the superficial velocities as the coordinates. As the liquid superficial velocity increases, transition to annular flow occurs at higher vapor superficial velocity. The same trend is seen for transition to the wispy-annular regime in the 400 and 
$1000 \mu \mathrm{m}$-wide microchannels; however, in the larger microchannels, this transition occurs at lower vapor superficial velocity as the liquid superficial velocity increases.

\subsubsection{Effect of channel dimension on flow regime transitions}

In order to readily illustrate the effect of channel size on the transitions between different flow regimes, the lines representing transition from bubbly or slug flows to intermittent churn/wispy-annular or churn/annular flows are plotted for the six microchannel widths in Figure 15(a) and (b) for the two types of flow regime maps. It is seen that as the microchannels become smaller, this transition occurs at a larger vapor quality or a larger vapor superficial velocity. Huo et al. (2004) also found that reducing the tube diameter shifts the transition of slug to churn and churn to annular flow to higher values of gas velocity. This dependence of the flow transition on channel size makes the flow maps in the literature limited to the test conditions and channel dimensions used. In Figure 15, these flow transitions are also compared to those of Mandhane, Gregory, and Aziz (1974) and Taitel and Dukler (1976) for adiabatic two-phase flow in large horizontal channels, Coleman and Garimella (2003) for condensation of R134a in $4.9 \mathrm{~mm}$ tubes, and Revellin et al. (2006) for boiling of R134a in round tubes of diameter $500 \mu \mathrm{m}$. It can be seen that only the transition line of Revellin et al. matches the current experimental results well and that of Coleman and Garimella only predicts the trend. It can be concluded that in general the flow maps developed for boiling or condensation in conventional sized channels or for adiabatic two-phase flow are not suitable for predicting the boiling in microchannels as also discussed in the literature (Hetsroni et al. 2003, Huo et al. 2004, Revellin et al. 2006, Field and Hrnjak 2007).

\section{CONCLUSIONS}

Flow boiling regimes obtained with the perfluorinated dielectric liquid FC-77 in six different microchannel heat sinks with channel widths ranging from $100 \mu \mathrm{m}$ to $5850 \mu \mathrm{m}$, all with a depth of 400 $\mu \mathrm{m}$, are investigated as a function of microchannel dimensions, mass flux and heat flux. Flow regime maps are developed based on the observed flow patterns and the effect of channel width on flow regime transitions highlighted. 
In general, five flow regimes - bubbly, slug, churn, wispy-annular, and annular flow - are identified. Flow patterns in the $100 \mu \mathrm{m}$ - and $250 \mu \mathrm{m}$-wide microchannels are found to be similar, and differ from those in microchannels of width $400 \mu \mathrm{m}$ and larger; the latter group showed similar flow patterns. As channel width increases, bubbly flow replaces slug flow and intermittent churn/wispy-annular flow replaces intermittent churn/annular flow.

For each microchannel size, as mass flux increases, the bubbles become smaller and more elongated in the bubbly region, and the liquid layer thickness in the wispy-annular and annular regimes decreases. Also, the transition between specific flow patterns occurs at a higher heat flux for higher mass fluxes.

It was shown in a prior study by the authors that for microchannels of width $400 \mu \mathrm{m}$ and larger, the heat transfer coefficient is almost invariant with channel size and a nucleate pool boiling correlation predicts the heat transfer coefficients very well. The flow visualizations in the current study show that nucleate boiling is dominant up to very high heat fluxes in microchannels of width $400 \mu \mathrm{m}$ and larger, and explain the observed heat transfer behavior. For the microchannels of width 100 and $250 \mu \mathrm{m}$, on the other hand, nucleate boiling is suppressed at relatively low heat fluxes. For microchannels of width $400 \mu \mathrm{m}$ and larger, it is shown that for the range of heat fluxes in which nucleate boiling occurs on the channel walls, the heat transfer coefficient is independent of mass flux regardless of the flow pattern.

Flow regime maps on mass flux-vapor quality and superficial velocity coordinates are developed based on the visualized flow patterns. It is seen that as the microchannels become smaller, the transition from bubbly or slug flow to intermittent churn/wispy-annular or churn/annular flow occurs at a larger vapor quality or a larger vapor superficial velocity. Comparison of flow transitions to those from the literature shows that flow regime maps developed for large channels or for adiabatic two-phase flow are not appropriate for predicting boiling regimes in microchannels.

In ongoing work, the influence of microchannel depth (or aspect ratio) on the flow patterns and heat transfer coefficients are being investigated. Surface roughness effects should also be examined. The development of predictive models for the boiling heat transfer coefficients based on the observed flow regimes will represent the next important advance in this field.

\section{Acknowledgements}


Financial support from members of the Cooling Technologies Research Center, an NSF Industry/University Cooperative Research Center at Purdue University, is gratefully acknowledged. The authors thank Bruce Myers and Darrel Peugh of Delphi Electronics and Safety, Kokomo, Indiana, for providing the silicon test pieces.

\section{REFERENCES}

Bertsch, S. S., Groll, E. A., and Garimella, S. V., 2008a, "Review and Comparative Analysis of Studies on Saturated Flow Boiling in Small Channels," Nanoscale and Microscale Thermophysical Engineering, 12 (3), pp. 187-227.

Bertsch, S. S., Groll, E. A., and Garimella, S. V., 2008b, "Refrigerant Flow Boiling Heat Transfer in Parallel Microchannels as a Function of Local Vapor Quality," International Journal of Heat and Mass Transfer, 51, pp. 4775-4787.

Chen, T. and Garimella, S. V., 2006a, "Measurements and High-Speed Visualization of Flow Boiling of a Dielectric Fluid in a Silicon Microchannel Heat Sink," International Journal of Multiphase Flow, 32 (8), pp. 957-971.

Chen, T. and Garimella S. V., 2006b, "Effect of Dissolved Air on Subcooled Flow Boiling of a Dielectric Coolant in a Microchannel Heat Sink,” Journal of Electronic Packaging, 128 (4), pp. 398-404.

Chung, P. M.-Y., Kawaji, M., 2004, “The Effect of Channel Diameter on Adiabatic Two-Phase Flow Characteristics in Microchannels," International Journal of Multiphase Flow, 30 (7-8), pp. 735-761.

Coleman, J. W. and Garimella S., 2003, “Two-Phase Flow Regimes in Round Square and Rectangular Tubes during Condensation of Refrigerant R134a," International Journal of Refrigeration, 26, pp. 117128.

Cooper, M. G., 1984a, "Saturated Nucleate Pool Boiling - a Simple Correlation," $1^{\text {st }}$ UK National Heat Transfer Conference, IChemE Symposium Series, 2 (86), pp. 785-793.

Cooper, M. G., 1984b, "Heat Flow Rates in Saturated Nucleate Pool Boiling - a Wide-Ranging Examination Using Reduced Properties,” Advances in Heat Transfer, 16, pp. 157-239. 
Field, B. and Hrnjak, P., 2007, "Visualization of Two-Phase Refrigerant and Refrigerant-Oil Flow in a Microchannel," ASME International Mechanical Engineering Congress and Exposition, IMECE200743471, Seattle, WA.

Garimella, S. V., Singhal, V., and Liu, D., 2006, “On-Chip Thermal Management with Microchannel Heat Sinks and Integrated Micropumps,” Proceedings of the IEEE, 94 (8), pp. 1534-1548.

Garimella, S. V. and Sobhan, C. B., 2003, “Transport in Microchannels - a Critical Review,” Annual Review of Heat Transfer, 13, pp. 1-50.

Harirchian, T. and Garimella, S. V., 2007, "Microchannel Size Effects on Two-Phase Local Heat Transfer and Pressure Drop in Silicon Microchannel Heat Sinks with a Dielectric Fluid," Proceedings of ASME International Mechanical Engineering Congress and Exposition, IMECE2007, 11, pp. 437-446.

Harirchian, T. and Garimella, S. V., 2008a, "Microchannel Size Effects on Local Flow Boiling Heat Transfer to a Dielectric Fluid," International Journal of Heat and Mass Transfer, 51, pp. 3724-3735.

Harirchian, T. and Garimella, S. V., 2008b, "An Investigation of Flow Boiling Regimes in Microchannels of Different Sizes by Means of High-Speed Visualization," $11^{\text {th }}$ IEEE Intersociety Conference on Thermal and Thermomechanical Phenomena in Electronic Systems, I-THERM, pp. 197206.

Hassan, I., Vaillancourt, M., and Pehlivan, K., 2005, “Two-Phase Flow Regime Transitions in Microchannels: a Comparative Experimental Study," Microscale Thermophysical Engineering, 9, pp. $165-182$.

Hetsroni, G., Mosyak, A., Segal, Z., and Pogrebnyak, E., 2003, “Two-Phase Flow Patterns in Parallel Microchannels," International Journal of Multiphase Flow, 29, pp. 341-360.

Honda, H. and Wei, J. J., 2004, "Enhanced Boiling Heat Transfer from Electronic Components by Use of Surface Microstructures," Experimental Thermal and Fluid Science, 28, pp. 159-169.

Huo, X., Chen, L., Tian, Y.S., and Karayiannis, T. G., 2004, "Flow Boiling and Flow Regimes in Small Diameter Tubes,” Applied Thermal Engineering, 24, pp. 1225-1239.

Jiang, L., Wong, M., and Zohar, Y., 2001, "Forced Convection Boiling in a Microchannel Heat Sink," Journal of Microelectromechanical Systems, 10, pp. 80-87. 
Kandlikar, S., 2004, "Heat Transfer Mechanisms During Flow Boiling in Microchannels," Journal of Heat Transfer, 126, pp. 8-16.

Kew, P. A. and Cornwell, K., 1997, "Correlations for the Prediction of Boiling Heat Transfer in Small-Diameter Channels," Applied Thermal Engineering, 17, pp. 705-715.

Lee, J. and Mudawar, I., 2008, "Fluid Flow and Heat Transfer Characteristics of Low Temperature Two-Phase Micro-Channel Heat Sinks - Part 1: Experimental Methods and Flow visualization Results," International Journal of Heat and Mass Transfer, 51, pp. 4315-4326.

Lee, M., Wong, Y. Y., Wong, M., and Zohar, Y., 2003, "Size and Shape Effects on Two-Phase Flow Patterns in Microchannel Forced Convection Boiling,” Journal of Micromechanics and Microengineering, 13, pp. 155-164.

Lin, S., Kew, P. A., and Cornwell, K., 2001, "Flow Boiling of Refrigerant R141b in Small Tubes," Chemical Engineering Research and Design, 79 (4), pp. 417-424.

Liu, D., Lee, P. S., and Garimella, S. V., 2005, "Prediction of the Onset of Nucleate Boiling in Microchannel Flow,” International Journal of Heat and Mass Transfer, 48, pp. 5134-5149.

McHale, J. P. and Garimella, S. V., 2008, "Measurement of Bubble Nucleation Characteristics in Pool Boiling of a Wetting Liquid on Smooth and Roughened Surfaces," 2008 ASME Summer Heat Transfer Conference, Jacksonville, FL, USA, HT2008-56179.

Mandhane, J. M., Gregory, G. A., and Aziz, K., 1974, “A Flow Pattern Map for Gas-Liquid Flow in Horizontal Pipes,” International Journal of Multiphase Flow, 1, p. 537-553.

Mishima, K., Ishii, M. 1984, "Flow Regime Transition Criteria for Upward Two-Phase Flow in Vertical Tubes,” International Journal of Heat and Mass Transfer, 27 (5), 723-737.

Peng, X. F. and Wang, B. X., 1993, "Forced Convection and Flow Boiling Heat Transfer for Liquid Flowing Through Microchannels," International Journal of Heat and Mass Transfer, 36 (14), pp. 34213427.

Revellin, R., Dupont, V., Ursenbacher, T., Thome, J. R., and Zun, I., 2006, "Characterization of Diabatic Two-Phase Flows in Microchannels: Flow Parameter Results for R-134a in a $0.5 \mathrm{~mm}$ Channel," International Journal of Multiphase Flow, 32, pp. 755-774. 
Saitoh, S., Daiguji, H., and Hihara, E., 2005, "Effect of Tube Diameter on Boiling Heat Transfer of R134a in Horizontal Small-Diameter Tubes," International Journal of Heat and Mass Transfer, 48 (23-24), pp. 4973-4984.

Sobhan, C. B. and Garimella, S. V., 2001, “A Comparative Analysis of Studies on Heat Transfer and Fluid Flow in Microchannels," Microscale Thermophysical Engineering, 5, pp. 293-311.

Taitel, Y., 1990, "Flow Pattern Transition in Two Phase Flow," Keynote lecture, $9^{\text {th }}$ International Heat Transfer Conference, Jerusalem, 19-24 August 1990, pp. 237-254.

Taitel, Y. and Dukler, A. E., 1976, “A Model for Predicting Flow Regime Transitions in Horizontal and Near Horizontal Gas-Liquid Flow,” AIChE Journal, 22, pp. 47-55.

Taylor, J. R., 1997, An Introduction to Error Analysis, $2^{\text {nd }}$ Ed., University Science Books.

Wang, G., Cheng, P., and Bergles, A. E., 2008, "Effects of Inlet/Outlet Configuration on Flow Boiling Instability in Parallel Microchannels," International Journal of Heat and Mass Transfer, 51 (9-10), pp. $2267-2281$.

Zhang, H. Y., Pinjala, D., and Wong T. N., 2005, "Experimental Characterization of Flow Boiling Heat Dissipation in a Microchannel Heat Sink with Different Orientations," Proceedings of $7^{\text {th }}$ Electronics Packaging Technology Conference, EPTC, 2, pp. 670-676.

Zhang, L., Wang, E. N., Goodson, K. E., and Kenny, T. W., 2005, "Phase Change Phenomena in Silicon Microchannels,” International Journal of Heat and Mass Transfer, 48, pp. 1572-1582. 


\section{LIST OF TABLES}

Table 1. Microchannel dimensions and mass fluxes (the four mass fluxes are referred to in the rest of the paper by the nominal values* of $225,630,1050$ and $\left.1420 \mathrm{~kg} / \mathrm{m}^{2} \mathrm{~s}\right)$.

\section{LIST OF FIGURES}

Figure 1. (a) Photograph, and (b) schematic diagram of the experimental setup.

Figure 2. (a) Photograph and (b) cross section of the microchannel test section.

Figure 3. Description of boiling flow regimes.

Figure 4. Flow patterns in the $100 \mu \mathrm{m} \times 400 \mu \mathrm{m}$ microchannels, $\mathrm{G}=630 \mathrm{~kg} / \mathrm{m}^{2} \mathrm{~s}$.

Figure 5. Flow patterns in the $400 \mu \mathrm{m} \times 400 \mu \mathrm{m}$ microchannels, $\mathrm{G}=630 \mathrm{~kg} / \mathrm{m}^{2} \mathrm{~s}$.

Figure 6. Flow patterns in the $5850 \mu \mathrm{m} \times 400 \mu \mathrm{m}$ microchannels, $\mathrm{G}=630 \mathrm{~kg} / \mathrm{m}^{2} \mathrm{~s}$.

Figure 7. Summary of boiling flow patterns at six microchannel widths for four mass fluxes.

Figure 8. Flow patterns at the onset of boiling in the $400 \mu \mathrm{m} \times 400 \mu \mathrm{m}$ microchannels.

Figure 9. Effect of mass flux on boiling flow patterns in the $400 \mu \mathrm{m} \times 400 \mu \mathrm{m}$ microchannels, $\mathrm{q} " \approx 145$ $\mathrm{kW} / \mathrm{m}^{2}$.

Figure 10. Variation of heat transfer coefficient and wall temperature with wall heat flux in the $400 \mu \mathrm{m} \times$ $400 \mu \mathrm{m}$ microchannels, $\mathrm{G}=630 \mathrm{~kg} / \mathrm{m}^{2} \mathrm{~s}$.

Figure 11. Effect of channel size on heat transfer coefficient for $\mathrm{G}=630 \mathrm{~kg} / \mathrm{m}^{2} \mathrm{~s}$; arrows denote the heat flux at which suppression of nucleate boiling occurs (Harirchian and Garimella 2008a).

Figure 12. Effect of mass flux on local heat transfer coefficient in the $400 \mu \mathrm{m} \times 400 \mu \mathrm{m}$ microchannels; the arrows mark the heat fluxes at which suppression of nucleate boiling is observed (Harirchian and Garimella 2008a).

Figure 13. Flow regime maps on mass flux-vapor quality coordinates with transition lines for six microchannels widths.

Figure 14. Flow regime maps on superficial velocity coordinates with transition lines for six microchannels widths. 
Figure 15. Effect of channel size on transition from bubbly or slug flow to intermittent churn/wispyannular or churn/annular flow on (a) the mass flux-vapor quality coordinate, and (b) the superficial velocity coordinates. Some relevant transition lines from the literature are also included. 
Table 1. Microchannel dimensions and mass fluxes (the four mass fluxes are referred to in the rest of the paper by the nominal values* of $225,630,1050$ and $1420 \mathrm{~kg} / \mathrm{m}^{2} \mathrm{~s}$ ).

\begin{tabular}{|c|c|c|c|c|c|}
\hline $\begin{array}{l}\mathrm{w}(\mu \mathrm{m}) \\
\text { (nominal } \\
\text { values) }\end{array}$ & $\begin{array}{l}\mathrm{w}_{\mathrm{f}}(\mu \mathrm{m}) \\
\text { (nominal } \\
\text { values) }\end{array}$ & $\begin{array}{c}\mathrm{H}(\mu \mathrm{m}) \\
\text { (nominal } \\
\text { values) }\end{array}$ & $\mathrm{N}$ & $\mathrm{G}\left(\mathrm{kg} / \mathrm{m}^{2} \mathrm{~s}\right)$ & $\begin{array}{l}\text { High-speed } \\
\text { visualization }\end{array}$ \\
\hline $\begin{array}{l}101.5 \\
(100)\end{array}$ & $\begin{array}{l}101.9 \\
(100)\end{array}$ & $\begin{array}{l}369.4 \\
(400)\end{array}$ & 60 & $214,621,1017,1405$ & $\checkmark$ \\
\hline $\begin{array}{l}239.1 \\
(250)\end{array}$ & $\begin{array}{l}110.8 \\
(100)\end{array}$ & $\begin{array}{l}371.4 \\
(400)\end{array}$ & 35 & $226,611,1126,1415$ & $\checkmark$ \\
\hline $\begin{array}{l}394.6 \\
(400)\end{array}$ & $\begin{array}{l}105.4 \\
(100)\end{array}$ & $\begin{array}{l}364.9 \\
(400)\end{array}$ & 24 & $227,633,1031,1431$ & $\checkmark$ \\
\hline $\begin{array}{l}686.3 \\
(700)\end{array}$ & $\begin{array}{l}154.1 \\
(150)\end{array}$ & $\begin{array}{l}375.6 \\
(400)\end{array}$ & 14 & $225,641,1053,1461$ & \\
\hline $\begin{array}{c}978.4 \\
(1000)\end{array}$ & $\begin{array}{l}222.3 \\
(200)\end{array}$ & $\begin{array}{l}373.7 \\
(400)\end{array}$ & 10 & $224,627,1037,1440$ & $\checkmark$ \\
\hline $\begin{array}{l}2202.8 \\
(2200)\end{array}$ & $\begin{array}{c}280 \\
(300)\end{array}$ & $\begin{array}{l}370.1 \\
(400)\end{array}$ & 5 & $227,633,1034,1427$ & $\checkmark$ \\
\hline $\begin{array}{l}5850.5 \\
(5850)\end{array}$ & $\begin{array}{c}300 \\
(300)\end{array}$ & $\begin{array}{l}376.2 \\
(400)\end{array}$ & 2 & $229,632,1028,1289$ & $\checkmark$ \\
\hline
\end{tabular}

Values of mass flux are calculated using the fluid properties at the saturation temperature. In previous reporting (Harirchian and Garimella 2007, 2008a, b), the nominal values were calculated at the room temperature of $25^{\circ} \mathrm{C}$. 


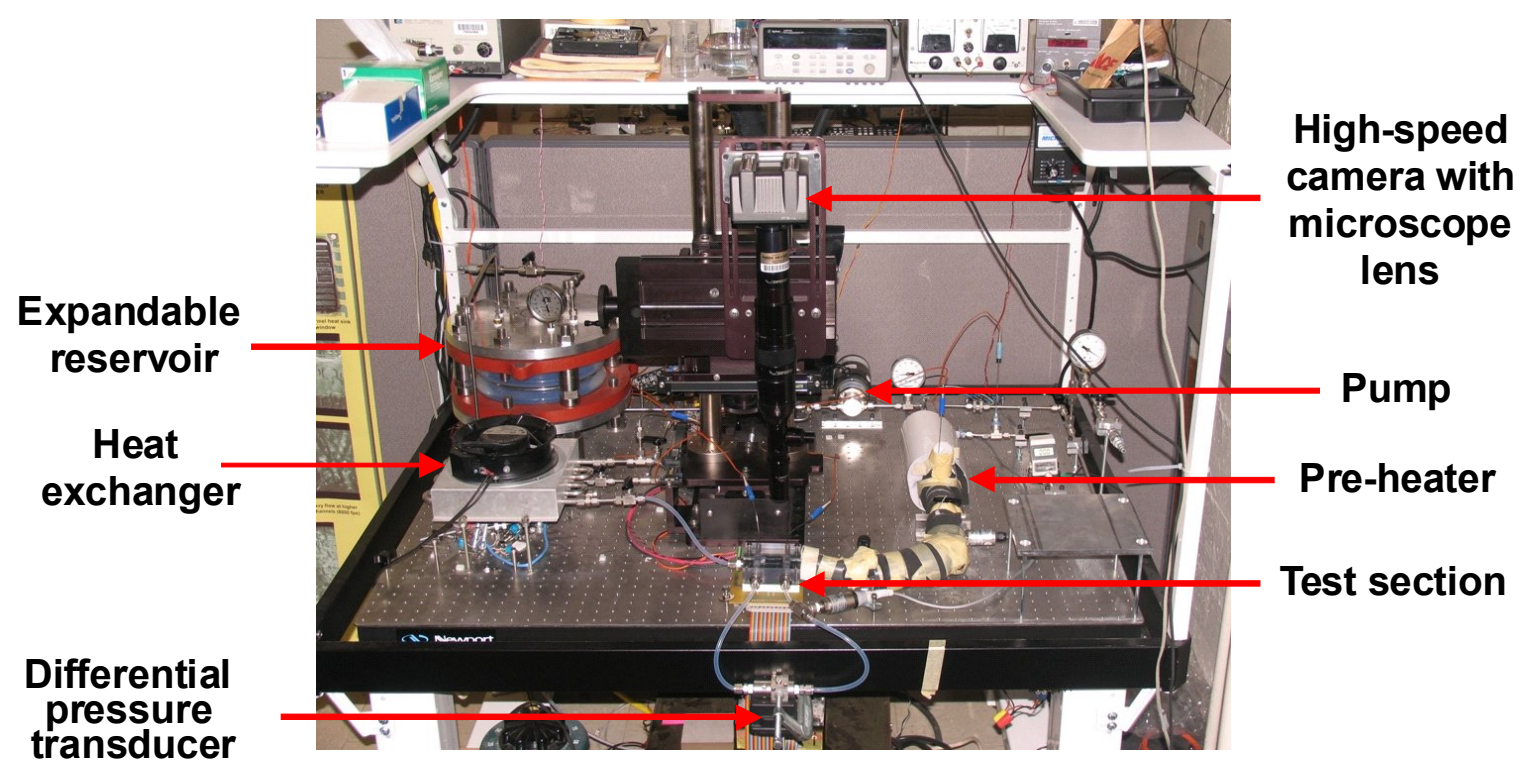

(a)

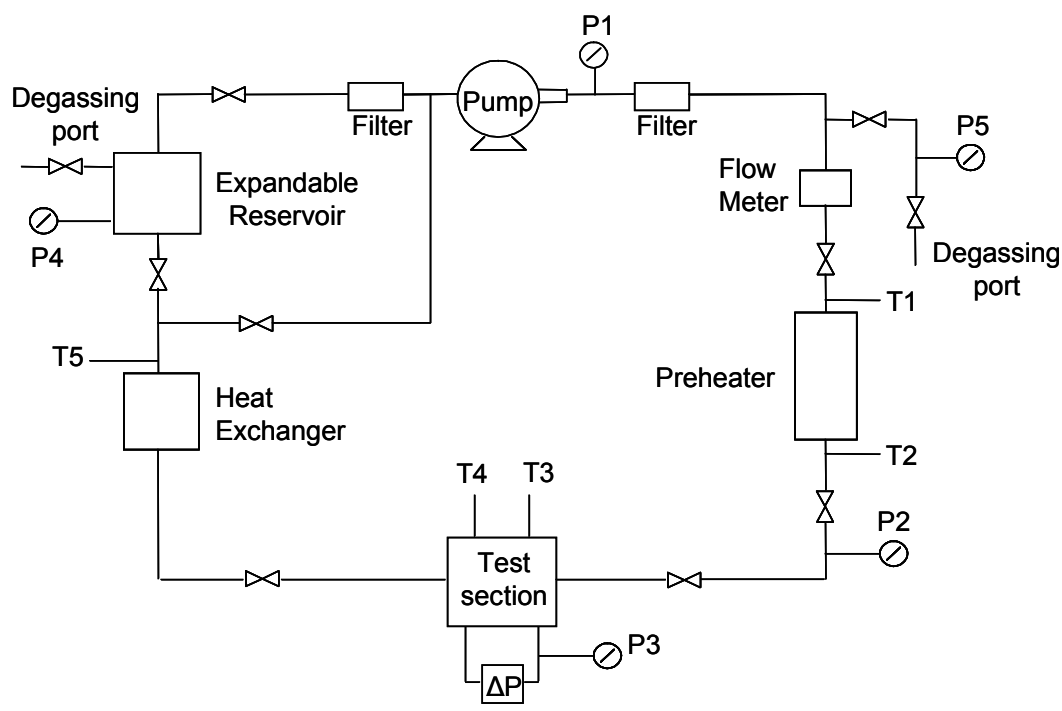

(b)

Figure 1. (a) Photograph, and (b) schematic diagram of the experimental setup. 


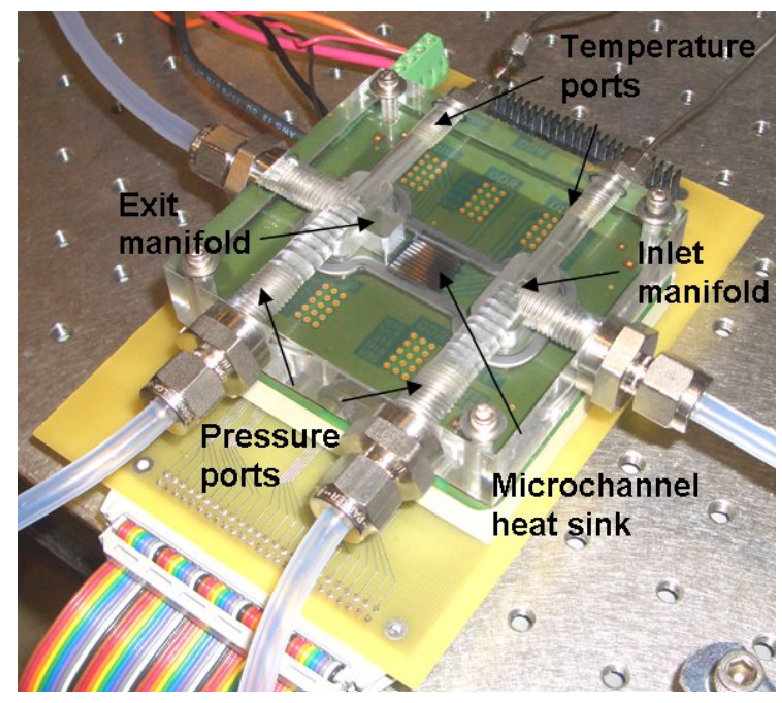

Figure 2. Microchannel test section. 


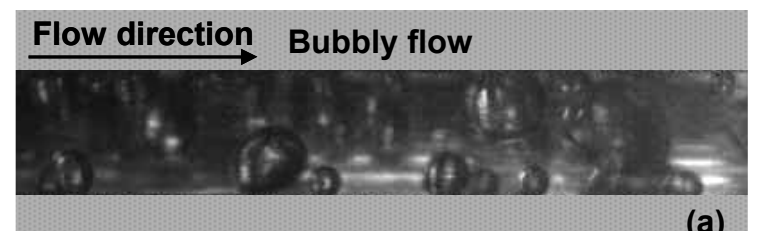

(a)

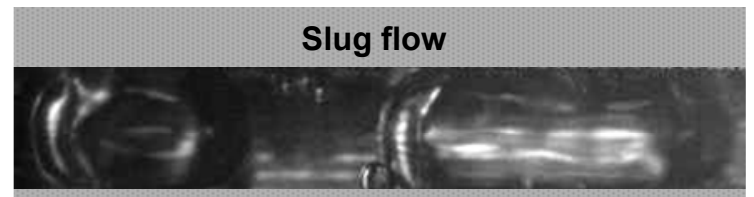

(b)
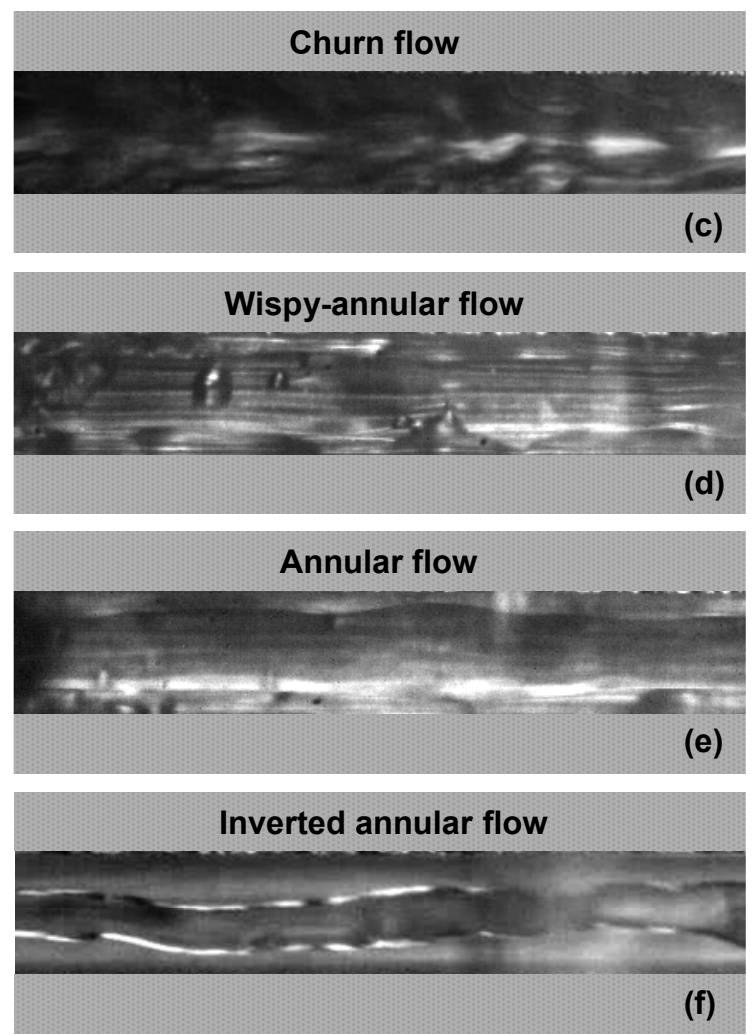
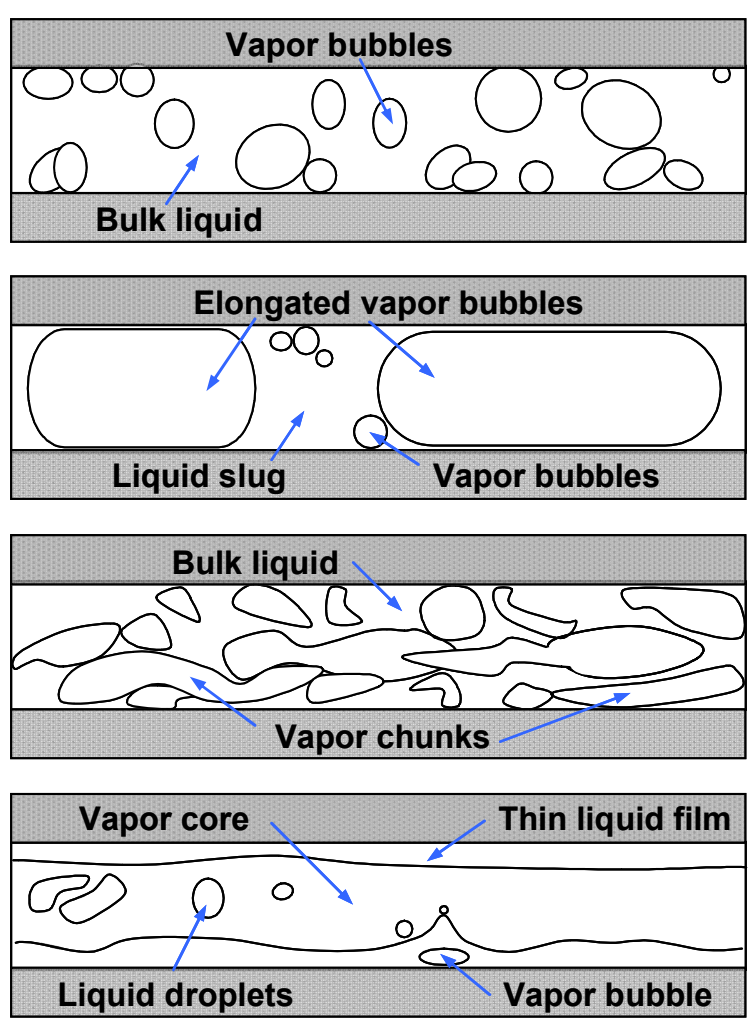

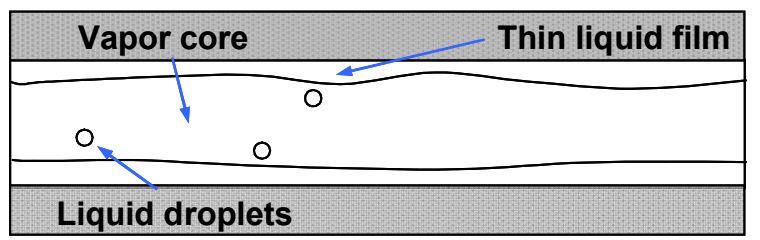

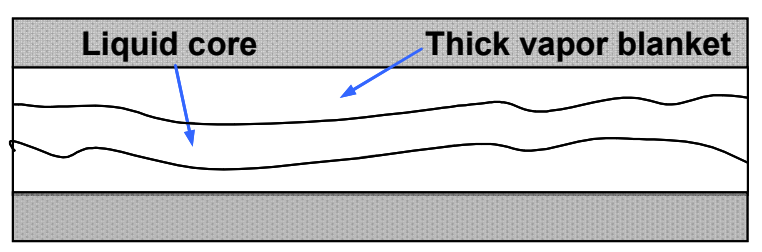

Figure 3. Description of boiling flow regimes. 


\begin{tabular}{lll} 
(Bubbles) & (Vapor slug) \\
\hline$q^{\prime \prime}=28.1 \mathrm{~kW} / \mathrm{m}^{2}$ & Slug flow & (a) \\
\hline (Vapor core) & (Nucleation sites) (Liquid rivulets) & (b)
\end{tabular}

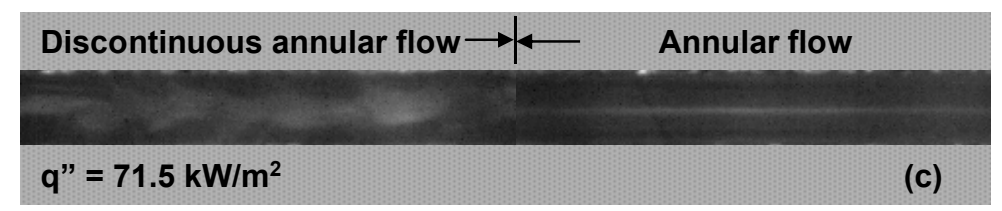

\begin{tabular}{|c|c|c|}
\hline Churn flow & $\longrightarrow \longleftarrow$ & Annular flow \\
\hline$q^{\prime \prime}=102.7 \mathrm{~kW} / \mathrm{m}^{2}$ & & (d) \\
\hline
\end{tabular}

Figure 4. Flow patterns in the $100 \mu \mathrm{m} \times 400 \mu \mathrm{m}$ microchannels, $G=630 \mathrm{~kg} / \mathrm{m}^{2} \mathrm{~s}$. 

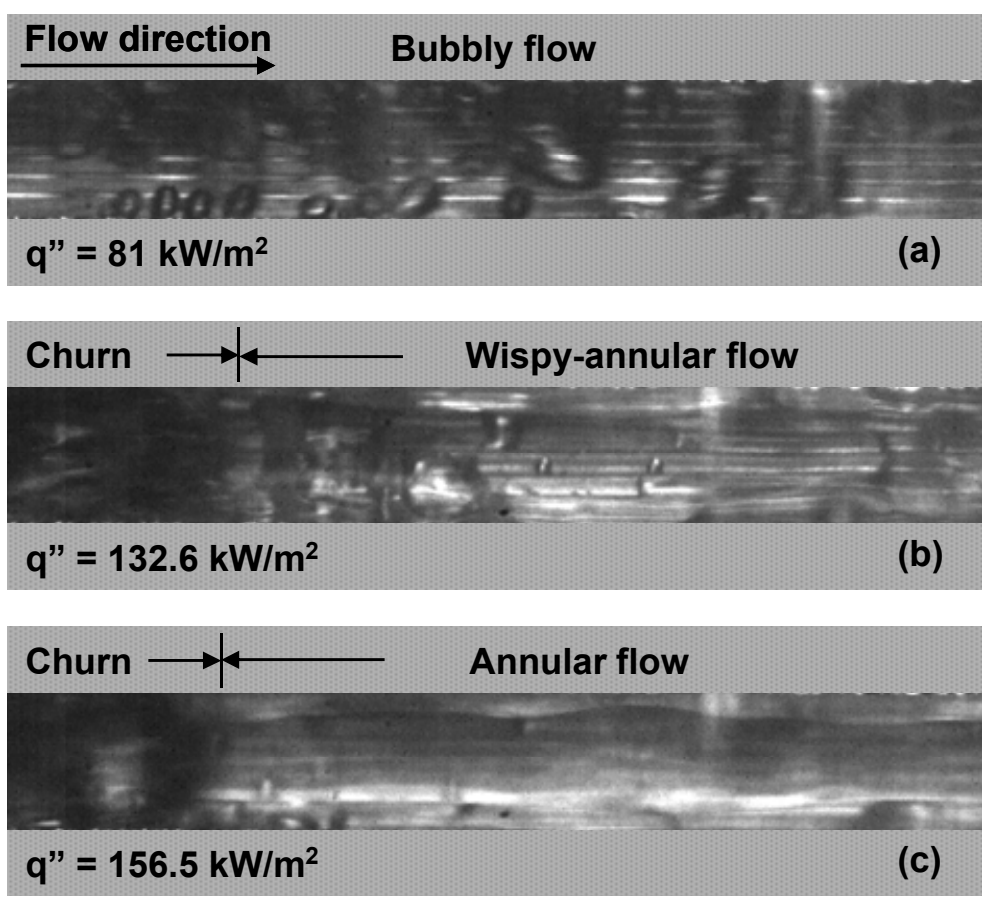

Figure 5. Flow patterns in the $400 \mu \mathrm{m} \times 400 \mu \mathrm{m}$ microchannels, $G=630 \mathrm{~kg} / \mathrm{m}^{2} \mathrm{~s}$. 

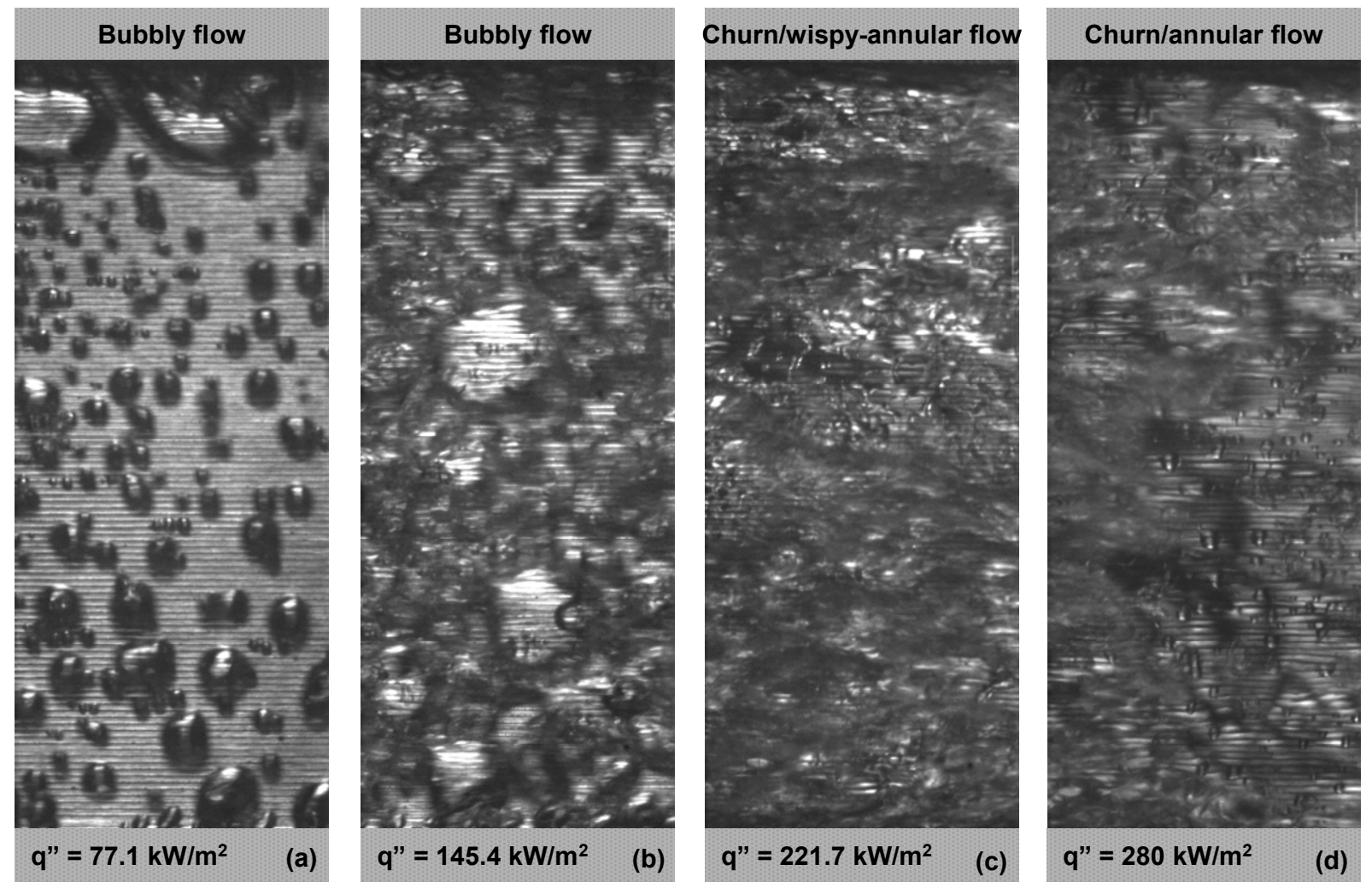

Figure 6. Flow patterns in the $5850 \mu \mathrm{m} \times 400 \mu \mathrm{m}$ microchannels, $G=630 \mathrm{~kg} / \mathrm{m}^{2} \mathrm{~s}$. 


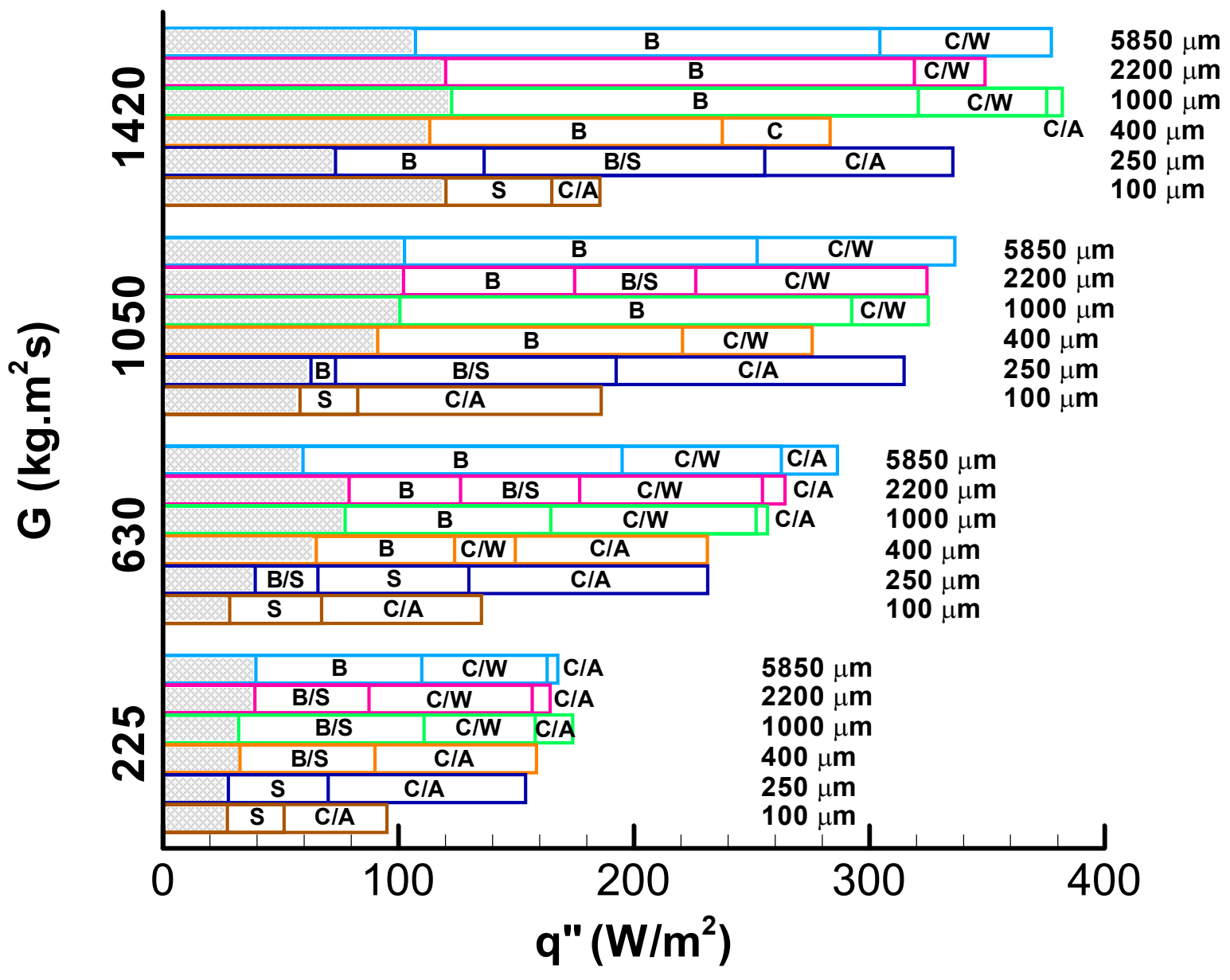

B: Bubbly S: Slug C: Churn W: Wispy-annular A: Annular
B/S: Intermittent bubbly/slug flow
C/W: Intermittent churn/wispy-annular flow
C/A: Intermittent churn/annular flow
$\quad$ : Single-phase flow

Figure 7. Summary of boiling flow patterns at six microchannel widths for four mass fluxes. 

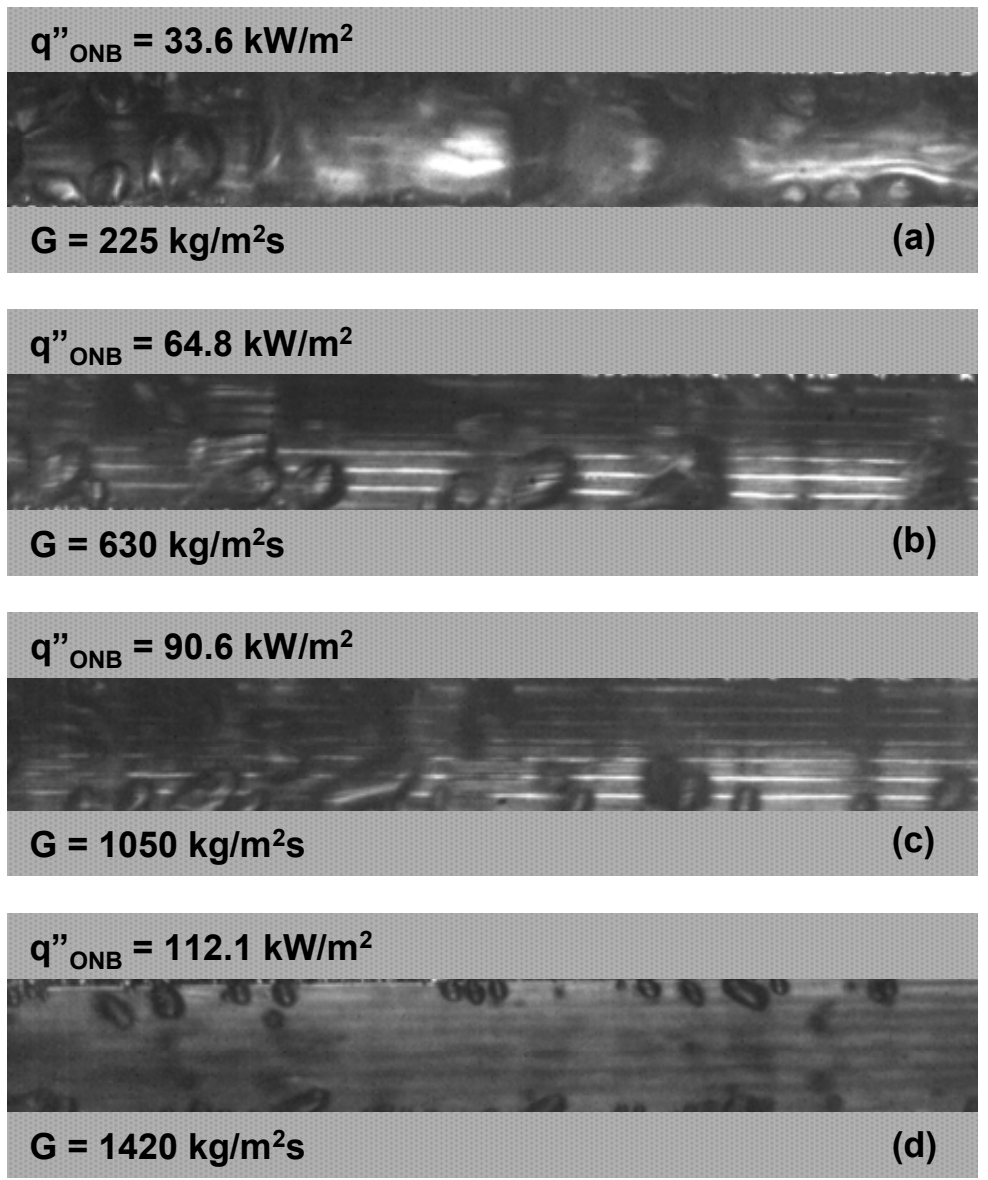

Figure 8. Flow patterns at the onset of boiling in the $400 \mu \mathrm{m} \times 400 \mu \mathrm{m}$ microchannels. 

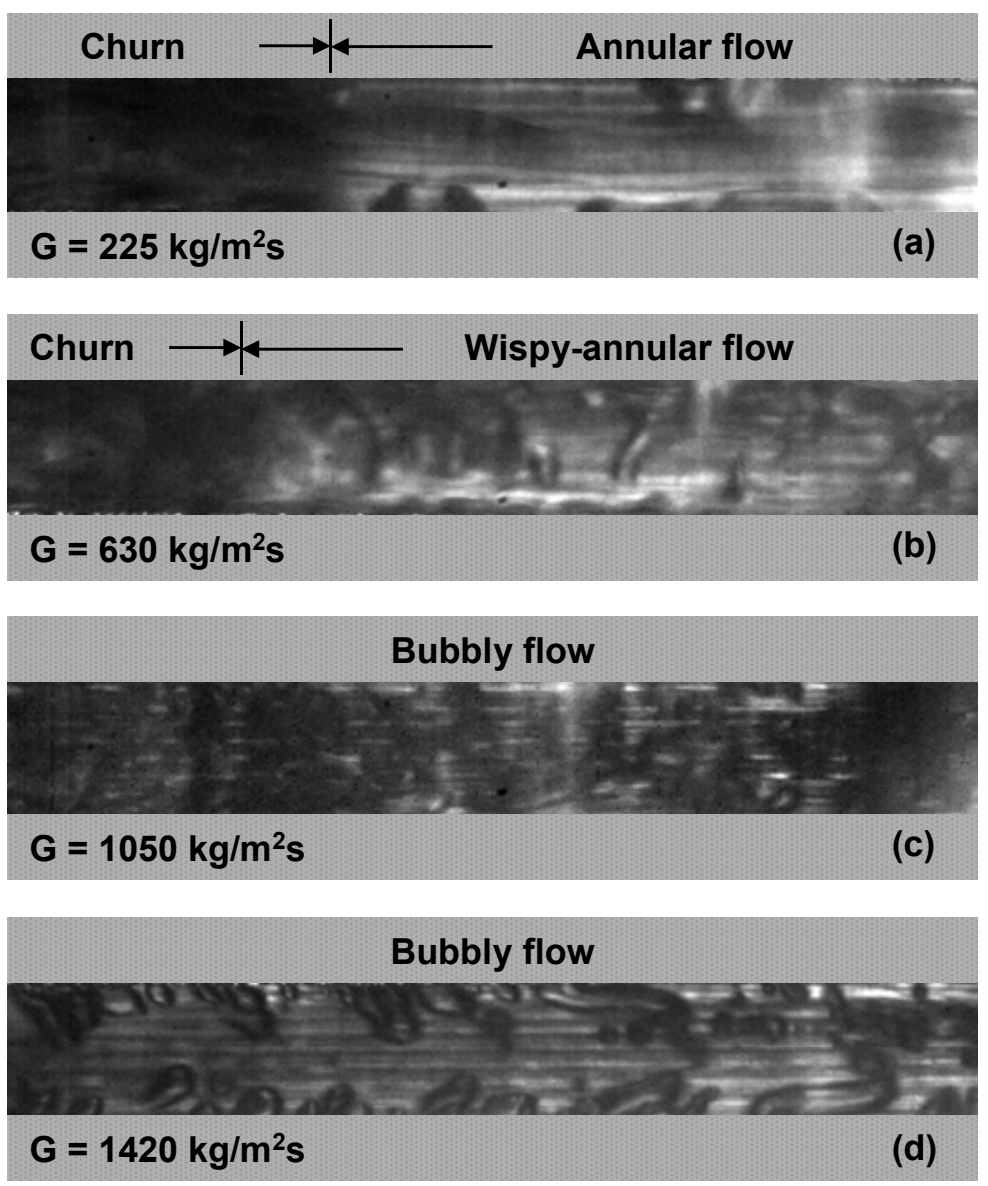

Figure 9. Effect of mass flux on boiling flow patterns in the $400 \mu \mathrm{m} \times 400 \mu \mathrm{m}$ microchannels, $q$ " $\approx$ $145 \mathrm{~kW} / \mathrm{m}^{2}$. 


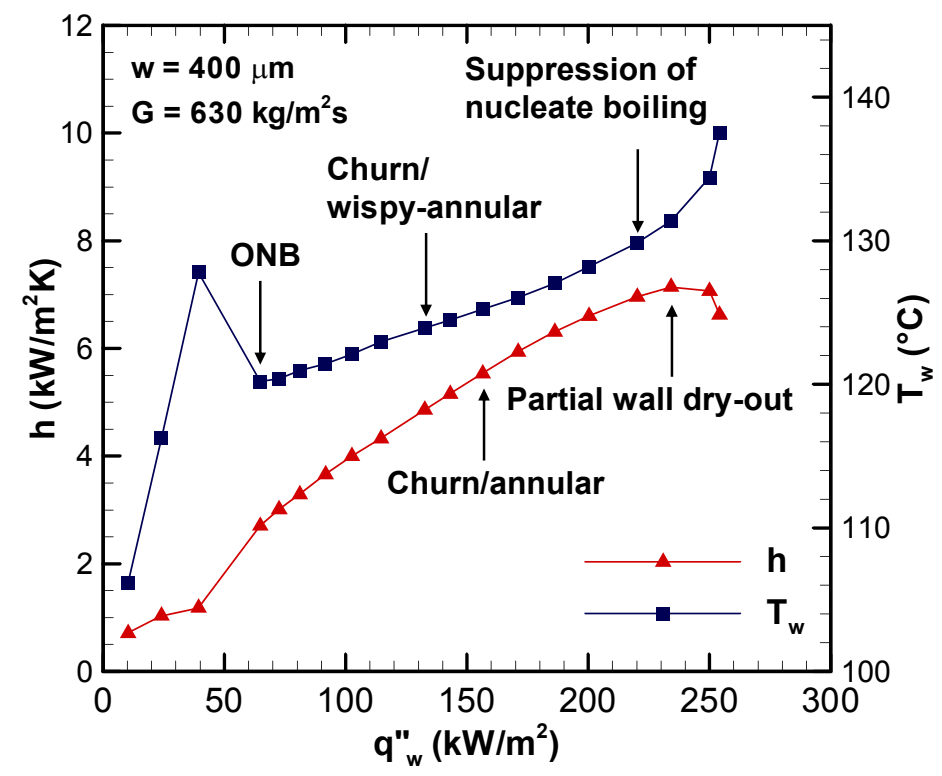

Figure 10. Variation of heat transfer coefficient and wall temperature with wall heat flux in the 400 $\mu \mathrm{m} \times 400 \mu \mathrm{m}$ microchannels, $G=630 \mathrm{~kg} / \mathrm{m}^{2} \mathrm{~s}$. 


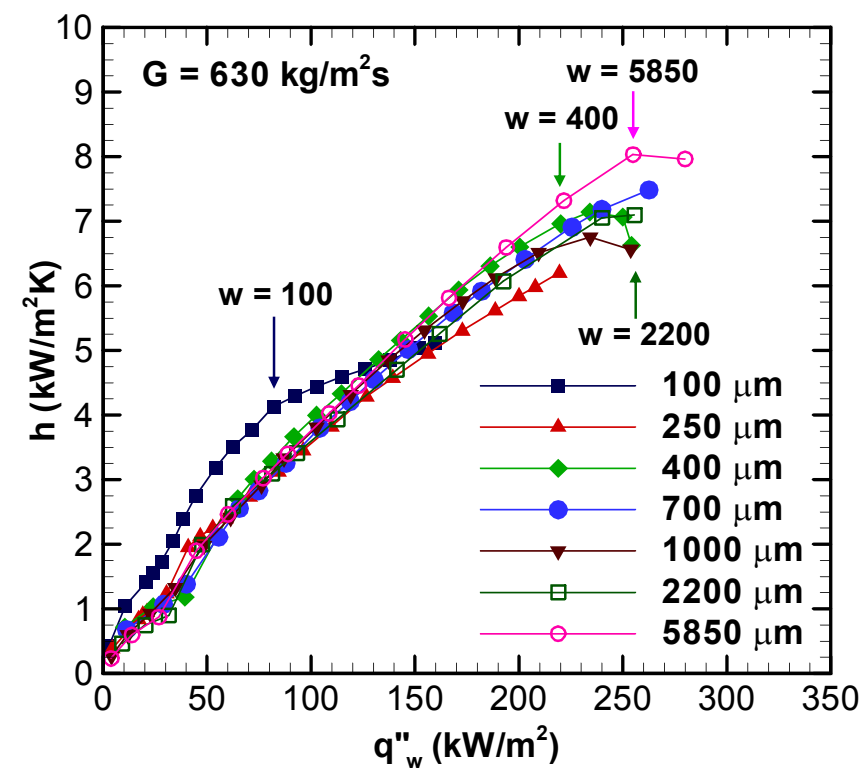

Figure 11. Effect of channel size on heat transfer coefficient for $G=630 \mathrm{~kg} / \mathrm{m}^{2} \mathrm{~s}$; arrows denote the heat flux at which suppression of nucleate boiling occurs (Harirchian and Garimella 2008a). 


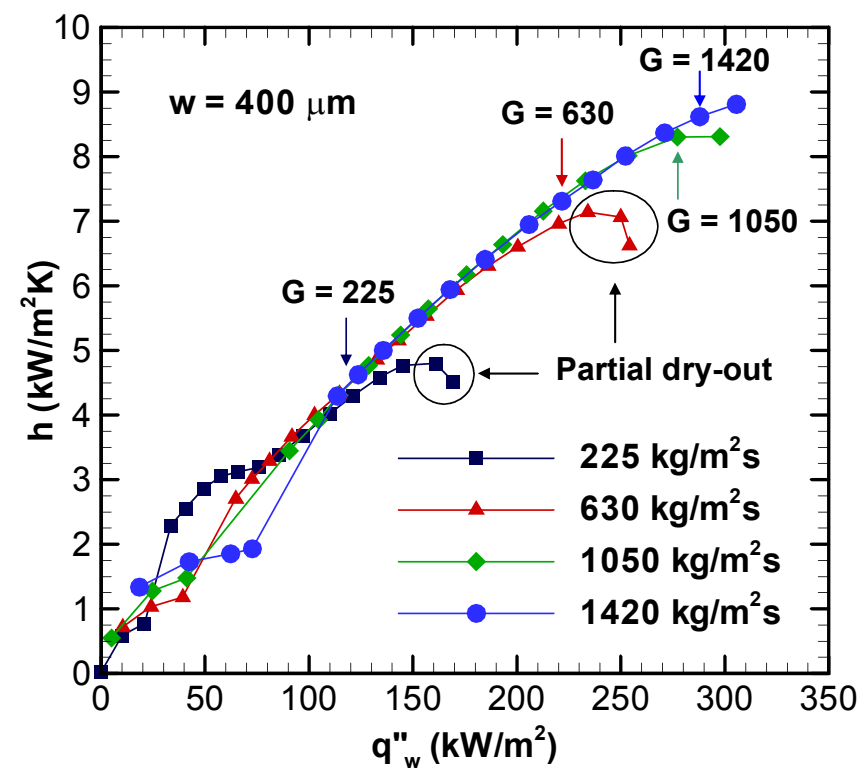

Figure 12. Effect of mass flux on local heat transfer coefficient in the $400 \mu \mathrm{m} \times 400 \mu \mathrm{m}$ microchannels; the arrows mark the heat fluxes at which suppression of nucleate boiling is observed (Harirchian and Garimella 2008a). 

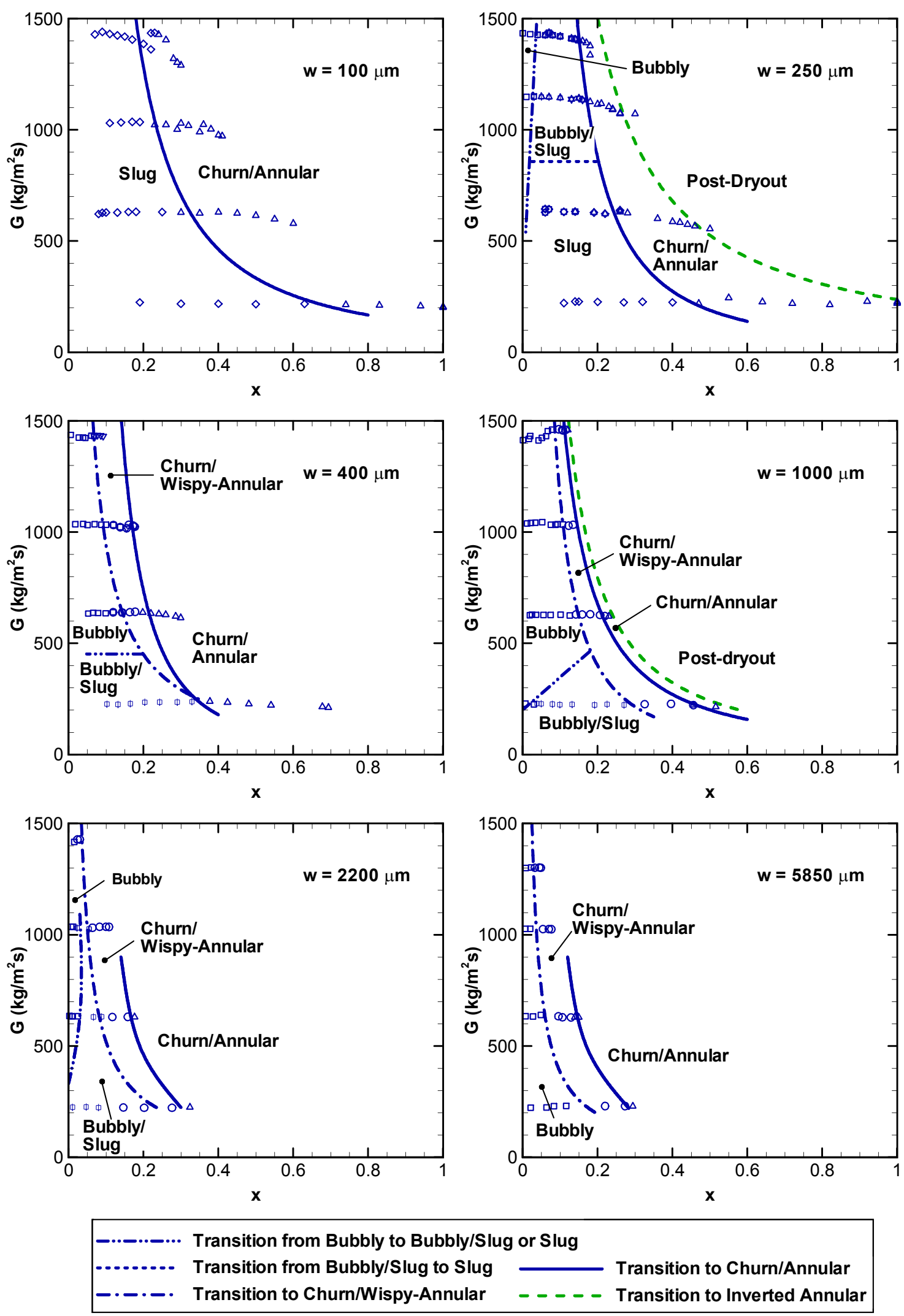

Figure 13. Flow regime maps on mass flux-vapor quality coordinates with transition lines for six microchannels widths. 

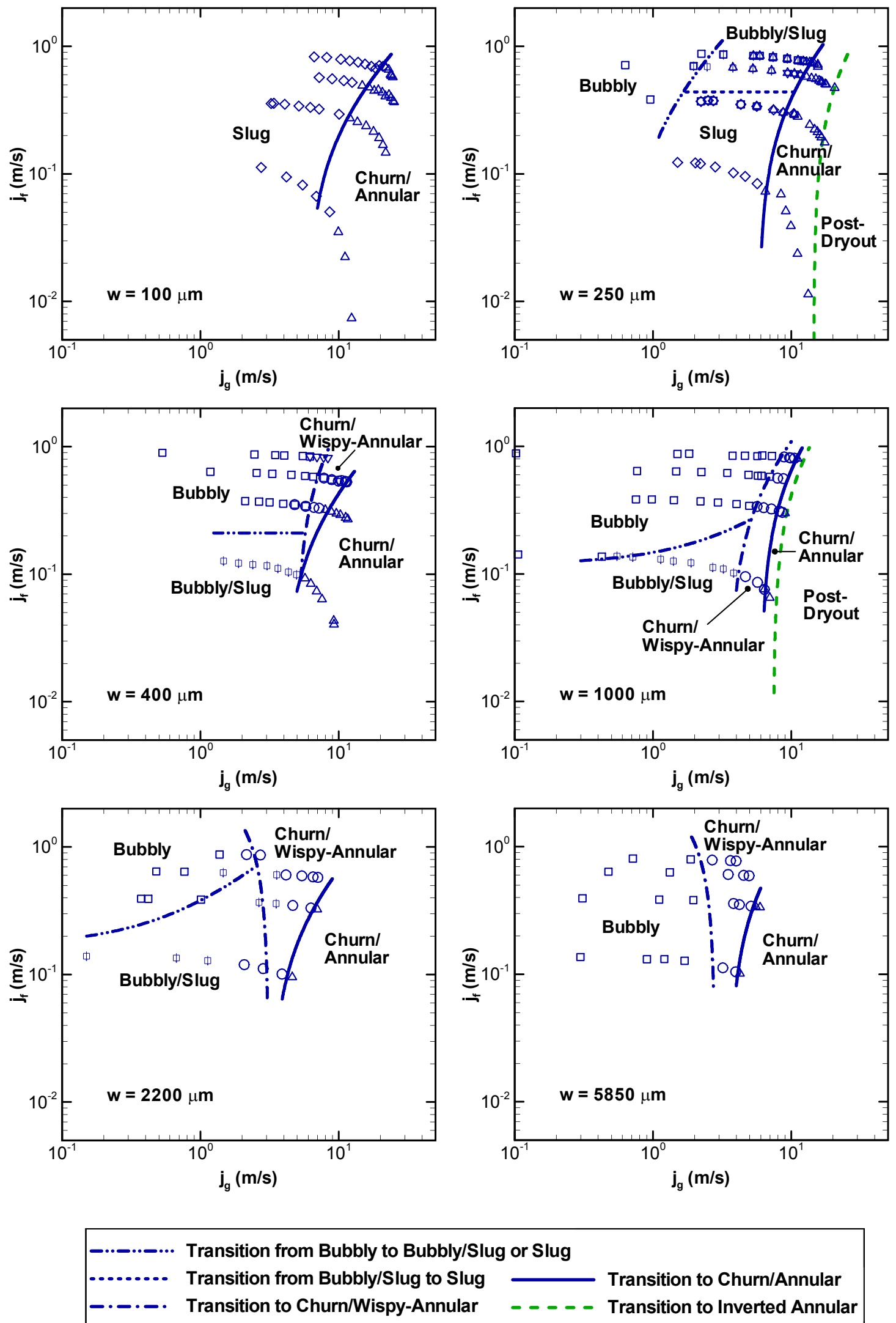

Figure 14. Flow regime maps on superficial velocity coordinates with transition lines for six microchannels widths. 


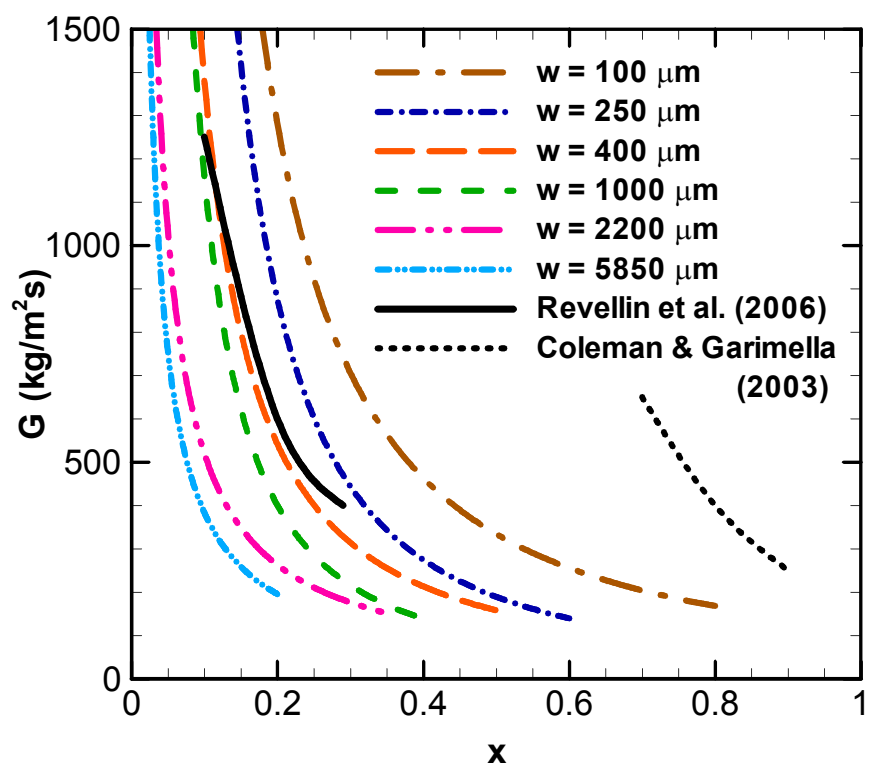

(a)

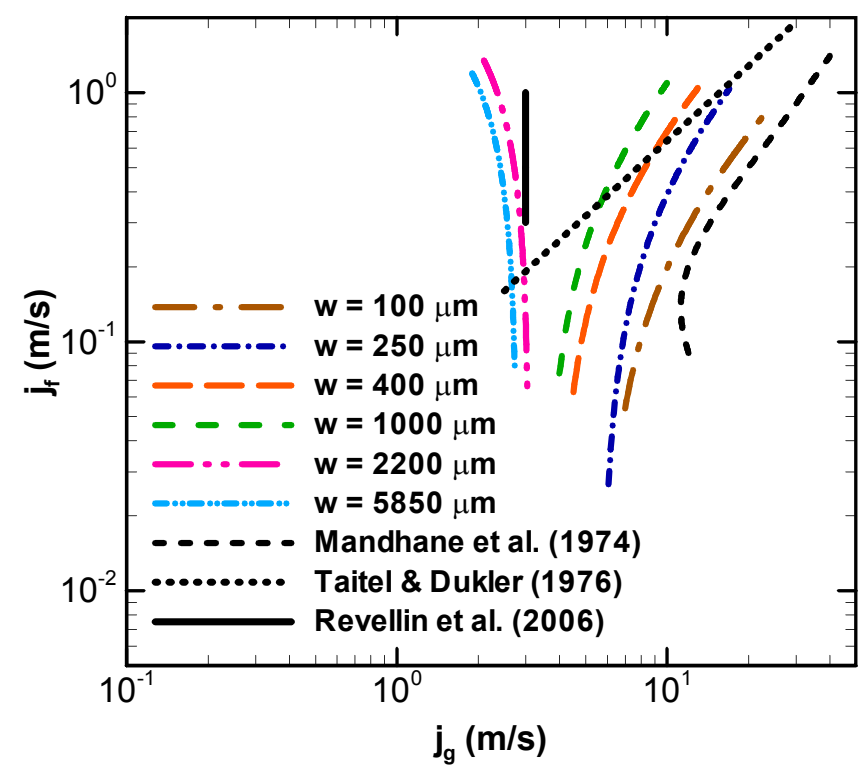

(b)

Figure 15. Effect of channel size on transition from bubbly or slug flow to intermittent churn/wispy-annular or churn/annular flow on (a) the mass flux-vapor quality coordinate, and (b) the superficial velocity coordinates. Some relevant transition lines from the literature are also included. 


\title{
Effects of Channel Dimension, Heat Flux, and Mass Flux on Flow Boiling Regimes in Microchannels
}

\author{
Tannaz Harirchian and Suresh V. Garimella
}

\section{Responses to Review 1}

(Verbatim review comments in italics followed by author responses)

This paper presents an experimental study on flow boiling patterns in microchannels using a dielectric fluid, with low surface tension. A range of microchannels sizes are investigated over a range of mass fluxes and heat fluxes. The paper is a nice extension of previous effort to reveal the heat transfer and fluid flow mechanisms governing flow boiling in diminishing length scales. The primary focus of this paper relates to flow pattern mapping - an important factor dictating the thermal-hydraulic characteristics of boiling at any length scale. It also ties nicely to the authors previous effort to characterize the heat transfer coefficient and pressure drop in similar microchannels configurations and conditions although it would have been more logical to start with flow pattern mapping before studying the mechanisms controlling the heat transfer coefficient. The paper is well written and is worthy of publication in the International Journal of Multiphase Flow, but, the authors should address the following concerns:

1) Flow boiling morphologies are much more dependent on mass quality than on heat flux. Since the heat flux and mass quality were not controlled independently in the experiments, it is not completely clear why the heat flux is emphasized as an independent variable controlling flow patterns and not the mass quality. While flow patterns are presented in terms of mass quality in Figures 14 and 15, the impression is that the heat flux is a much more important parameter dictating flow patterns.

For the electronics cooling application which is the main target of this paper, the controlling variable would be the applied heat flux and this is why the flow regimes are summarized based on the applied heat flux in figure 7 (this is also consistent with a good portion of the literature in this field); however, our intention is not to emphasize heat flux as a governing parameter any more than vapor quality. In fact, due to the important effects of vapor quality on the flow regimes, vapor quality is used as an independent variable in the flow regime maps (figures 13 and 15).

2) The silicon device configuration should be clearly outlined. How do the inlet and exit manifolds connect to the parallel channels? The length of the channels should be provided. Are they $12.7 \mathrm{~mm}$ ? If so, how do they connect to the manifold? What is the spacing between adjacent channels? What is the channel cross-sectional shape? Is it trapezoidal, rectangular, or some other shape? An SEM image, or any other clear image, depicting the channel's cross-section should be included. How many parallel channels are there?

The width of the walls between any two adjacent channels, as well as the number of channels in each heat sink, is included in Table 1. The length and shape of the channels and the details of the inlet and exit manifolds are added in the revision to Section 2.2.

3) In the introduction, the discussion pertinent to adiabatic two-phase flow in microchannels overlooked the important findings regarding flow pattern from Kawaji's group (P.M.-Y. Chung, M. Kawaji, The effect of channel diameter on adiabatic two-phase flow characteristics in microchannels, Int. J. 
Multiphase Flow 30 (2004) 735; A. Kawahara, P.M.-Y. Chung, M. Kawaji, Investigation of two phase flow pattern, void fraction and pressure drop in a microchannel, Int. J. Multiphase Flow 28 (2002) 1411). (A disclosure: the reviewer is not affiliated with Kawaji's group in any way.)

The present study is focused on boiling in microchannels rather than adiabatic two-phase flow. In the introduction, only two studies pertinent to the development of flow regime maps for adiabatic two-phase flow were discussed. The reason for this inclusion was to emphasize the inability of the adiabatic flow regime maps to predict boiling in microchannels. We have now included the study of Chung and Kawaji (2004) in this section.

\section{4) How was the overall surface efficiency evaluated?}

The definition of the overall surface efficiency is added in the revision to section 2.4.

5) While it is stated that more details on the heat loss measurement procedure and data reduction can be found in Harirchian and Garimella (2008a), the absolute heat loss values and as a percentage of the net heat flux need to be provided.

The heat loss ranges from $7 \%$ to $50 \%$ of the net heat transfer rate. These values are added in the revision in section 2.4.

6) The uncertainties in the heat transfer coefficients seem quite low even in respect to conventional scale experiments. How was the heat loss factored into the heat transfer coefficient uncertainty analysis?

Although the heat loss can be up to $50 \%$ of the net heat transfer rate, the uncertainty in the heat loss, which is measured, is very small. Since the heat loss values are not estimated but instead measured for all test conditions, uncertainties due to heat loss are very small, and do not represent a large contribution to the uncertainty in the heat transfer coefficient.

\section{7) What is the uncertainty of the mass flux?}

The uncertainties in the mass flux range from $2 \%$ to $5 \%$; however, we note that the mass flux does not play a role in the heat transfer coefficient calculation. Also, since the results of this study show that the heat transfer coefficient is largely independent of mass flux, the uncertainty in mass flux is not critical to this study. Nonetheless, information on mass flux uncertainty is added in the revision in section 2.4.

8) I have hard time believing that the uncertainty in the diode temperature sensor measurement is +/$0.02 \mathrm{~K}$. This is just an incredibly good measurement.

The reported uncertainty in the diode temperature sensors comes from the calibration relationship developed for these sensors and the error in the data acquisition system; however, we agree with the reviewer that a more appropriate reporting would include the uncertainty in the oven temperature measurement used in the calibration process, which leads to an uncertainty of $\pm 0.3 \mathrm{~K}$. We have made this 
change in the revision. This change leads to the maximum heat transfer coefficient uncertainty now being $4.8 \%$. The uncertainty analysis in the revised paper has been updated in section 2.4 .

9) The photographic figures are not very clear. Specifically, Figures 4, 5, 6, 8, 9. Figure 3 at least has a sketch that helps conceptualize the flow patterns.

The main difficulty in obtained good photographs is the lighting - since we are imaging microscale flows, and also in a heat sink with parallel microchannels (as opposed to a single glass tube as has been used in some reported studies), and since the photos are frames from video, there are limitations to the quality of the still photos that can be obtained. In order to explain the different flow regimes present in the microchannels, schematics are included in Figure 3. Flow morphologies in other figures are more or less similar to those in figure 3 and specific characteristics and differences are explained in detail in the text to make the comprehension of these images easier.

Also, there may have been a problem with the conversion to pdf on the journal webtool. We will provide high-resolution images directly to the publisher for publication, and this may alleviate some of the issues with pdf conversion.

In conclusion, the manuscript reports useful results and should be accepted after implementing the above comments.

We thank the reviewer for the comments provided, and believe that the manuscript is stronger as a result of the changes suggested and made to the manuscript. 


\section{Responses to Review 2}

The authors seem to have done a comprehensive work in experimentally determining boiling flow patterns in microchannels at different heat flux, mass flux, and channel sizes. It is helpful to see the inclusion of detailed description of flow patterns in the text. In lieu of the completeness of the work and its significance to potential applications, I would suggest publication of this work under the condition of clarifications on the following comments.

\section{Comments:}

1. The test pieces used in the work have different width, but the same depth. So, it is suggested that "channel dimension" be changed to "channel width".

We have made changes throughout the revised text, including the abstract, to indicate that the primary dimension changed is the channel width. However, it is not clear yet whether the effects seen in this study depend only on channel width, or on hydraulic diameter, or on the smallest dimension of the channel. Hence, we have chosen to retain the more general "dimension" in the title.

2. In the abstract, "local measurements of heat transfer coefficient and pressure drop". Should it be "measurements of local heat transfer coefficient"? Since pressure drop data were not provided, it is suggested to delete "and pressure drop".

Mention of pressure drop in the abstract was an oversight, and is now deleted.

3. Also in the abstract, "The visualizations show that ...": it sounds like that visualizations ONLY determines that flow boiling in microchannels is nucleate boiling dominant. Is it true?

The abstract is revised to clarify that the heat transfer data confirm the flow visualizations.

4. In the "2.2 Test Section", the channels cut with a dicing saw can have a roughness of 0.1 to 0.2 um? Authors need to double check.

As discussed in Section 2.2, microchannels wider than $100 \mu \mathrm{m}$ were each made with a number of cuts; this process imparts a waviness to the bottom surfaces resulting in an average roughness of 0.8 to $1.4 \mu \mathrm{m}$ for the different test pieces; however, the average roughness in the region of a single cut in these wider channels is $0.2 \mu \mathrm{m}$.

5. In the "2.3 Experimental Procedure" - boiling flow patterns were visualized at different mass fluxes. Does this refer to the mass flux in the channel being visualized or average mass flux through the microchannel heat sink? Table 1 shows each test piece has multiple channels. Is there any maldistribution that could affect the mass flux in the channel being visualized?

The mass flux referred to is the average mass flux through all the channels. From other studies in our group, the current mainfold design has been shown to lead to fairly uniform flow in the microchannels, at least for single-phase flow. Moreover, comparison of the visualized boiling regimes in different channels does not show any significant differences in boiling in the different channels. We have now emphasized in the text that the mass flux values referred to are the average values. 
6. From equations (2) and (3), heat flux is based on the actual heat transfer area. It seems that most of literature work for electronics cooling use footprint area to calculate heat flux. Can the heat sink footprint area be used?

To study the physics of boiling and to develop flow regime maps, it is important to use the heat flux based on the actual heat transfer area. However, as the reviewer points out, the heat flux based on the heat dissipating area is important for electronics cooling. For this reason, in another publication (IJHMT 51:3724-3735, 2008), we have considered both heat fluxes in our discussion, and compared the effect of channel size based on both heat flux definitions.

7. In section "3.1.1 effect of channel width on flow patterns" - for 100 um channels, bubbly flow is not established. Do the authors mean that bubbly flow is not seen at the visualization location? Should there be a segment in the microchannel where bubbles are nucleated?

Bubbly flow might exist in the upstream portion, but at the visualization location, bubbly flow is not sustained and slug flow is established early after the incipience of boiling. This is clarified in Section 3.1.1.

8. In Page 12, the statement of "at this heat flux, the nucleation boiling-dominant regime ends and boiling enters ...." - it seems somehow far fetching in reaching a conclusion about nucleation boiling or convective boiling dominant just based on the observations.

The relevant text has been revised to make this a less definitive statement and to also related it to subsequent heat transfer results.

9. Page 13, 3rd paragraph - "In general, it is noted from this figure that the incipience heat flux and the critical heat flux increase ..." Authors may need some explanation about the critical heat flux which does not seem obvious in the context.

Both incipience heat flux and critical heat flux are now described in section 3.1.1.

10. In obtaining the map of flow patterns which is only locally visualized, is the heat flux uniform over the base area of the heat sink? Authors need clarifications on this - because the upstream flow patterns certainly affects the local visualizations being report in the work, and upstream flow patterns is determined by the heat flux provided in the upstream portion of the heat sink base.

Yes, the heat flux was indeed maintained uniform over the entire base area of the heat sink, i.e., over the entire test chip, and this has now been clarified in the second paragraph of section 2.3.

We thank the reviewer for the comments provided, and believe that the manuscript is stronger as a result of the changes suggested and made to the manuscript. 